\title{
DIE STADT ALS UTOPIE
}

Im Laufe der gesamten Menschheitsgeschichte hat man von einer idealen Welt geträumt - vom Land des Glücks. Die Schlusszeilen des Poems Utopia (1516) aus der Feder eines der bekanntesten Utopisten des 16. Jahrhunderts, Sir Thomas Morus, klingen eben wie folgt: Eutopia is my name: a land of happiness. ${ }^{1}$

Utopische Ideen von idealen Gesellschaften, Staaten oder Städten sind überwiegend als Philosophien und Theorien oder als künstlerische und literarische Phantasien vorgelegt worden, aber man hat auch versucht, sie in die Wirklichkeit umzusetzen. Auf diese Art und Weise haben soziale, politische oder humanistische Utopien die Planung und Bebauung von Städten beeinflusst. Besonders radikale Veränderungen sind eben während sozialer und urbaner Krisen und am Beginn von neuen politischen Formationen und städtebaulichen Perioden entworfen worden. Also sind die utopischen Ideen des Städtebaus immer an gewisse politische Herrschaftsformen - an den Absolutismus und den Totalitarismus - geknüpft gewesen, was die Umwandlung der Utopie in die Antiutopie oder Dystopie zur Folge hat. ${ }^{2}$

Während die utopischen Baupläne der Idealstädte zwar im Dienst der neuen Ideologien stehen, können sie trotzdem als eine visuelle und ästhetische Form der Verwirklichung von sozialen und politischen

DOI: http://dx.doi.org/10.12697/BJAH.2013.5.05

Übersetzung aus dem Estnischen von Marju und Olaf Mertelsmann.

1 Thomas More, Utopia. Ideal Commonwealths, introduction by Henry Morley (London, New York: Routledge, 1885).

2 Die Dystopie, Antiutopie oder auch Kakotopie ist eine fiktive Gesellschaft, ebenso ein Werk, das sie darstellt, für die der Totalitarismus und die unterdrückenden Methoden der sozialen Kontrolle charakteristisch sind. 
Ideen betrachtet werden. ${ }^{3}$ Ähnlich wie im übrigen Europa liefert eine Übersicht über die unterschiedlichen Bauperioden der Städte Estlands die Grundlage für die Behauptung, dass die Veränderungen, die in ihrer Entwicklung stattgefunden haben und das Planen mit den charakteristischen Erscheinungen der Utopie in Zusammenhang gebracht werden können, ${ }^{4}$ worauf der vorliegende Artikel abzielt.

\section{DIE ZEITALTER DER UTOPIEN}

Fast die gesamte intellektuelle Entwicklung des Westens ist durchtränkt vom utopischen Gedanken und seinen Erscheinungen. ${ }^{5}$ In der Realität wird die Verwirklichung der Ideale für irreal gehalten, worauf auch die Bedeutung des Terminus verweist - bei einer Utopie ${ }^{6}$ handelt es sich um eine schöne Ortschaft, die in der Realität nicht existiert. In der Entwicklung der Utopien werden drei Phasen unterschieden: die früheren Geschichten vor der Renaissance, die klassischen Utopien, deren Entstehung mit der Renaissance verbunden ist, und die späteren, modernen Utopien, die bis heute weiterexistieren. ${ }^{7}$

$\mathrm{Zu}$ den früheren werden die mythologischen und religiösen Utopien gezählt, wie zum Beispiel das Golden Zeitalter (aetas aurea), die Stadt Gottes von Augustinus (civitas dei) oder der Garten Eden als das Paradies auf Erden sowie die antiken Abhandlungen über die Gesellschaft, wie der von Platon beschriebene untergegangene Kontinent Atlantis.

Die klassischen Utopien sind Traumbilder von idealen Gesellschaften, die sich normalerweise an schwer zugänglichen Orten oder an unbekannten geographischen Ortschaften befinden und die an keine konkrete Zeit oder Lokalität geknüpft sind. Solche Art von Utopien nahm ihren Anfang mit den Träumen von idealen Gesellschaften während der Zeit der Renaissance, als das Werk von Sir Thomas Morus,

3 Hanno-Walther Kruft, Städte in Utopia. Die Idealstadt vom 15. bis zum 18. Jahrhundert zwischen Staatsutopie und Wirklichkeit (München: Verlag C. H. Beck, 1989), 10.

4 Lilian Hansar, Linnast muinsuskaitsealaks. Linnaehituslike struktuuride muutused Eesti väikelinnades 13.-20. sajandini, Eesti Kunstiakadeemia toimetised, 4 (Tallinn: Eesti Kunstiakadeemia, 2010). 5 Leonidas Donskis, „Sotsiaalsed müüdid“, Akadeemia, 12 (1990), 2520, 2524.

6 Den Terminus der Utopie führte Thomas Morus in seinem Werk Utopia (1516) ein. Utopie (auf Griechisch: ou-topos, ein Nicht-Ort, ein nicht existierender Ort oder eu-topos, ein schöner Ort, ein guter Ort).

7 Virve Sarapik, „_topias and Islands“, Koht ja paik = Place and Location III, Eesti Kunstiakadeemia toimetised, 14, herausgegeben von Virve Sarapik, Kadri Tüür (Tallinn: Eesti Kunstiakadeemia: 2003), 111-112. 
Utopia (1516), den Grundstein für zahlreiche folgende und unerfüllbare Traumbilder von der Gleichheit der Menschen, von der Religionsfreiheit und der Demokratie legte. ${ }^{8}$ In diesen Zeitraum fällt auch der Idealstaat Nova Atlantis (Das neue Atlantis) des Begründers der theoretischen Wissenschaftsphilosophie, Francis Bacon, den Wissenschaftler durch ihr Forschungsinstitut, das Haus Salomons, führen. ${ }^{9}$

Das bekanntere Beispiel einer utopischen Idealstadt, die von Tommaso Campanella beschriebene Sonnenstadt (1623), ist in Form von konzentrischen Kreisen aufgebaut, wo jeder Mauerkreis den Namen eines anderen Planeten trägt und den zentralen Punkt der Stadt, den Rundtempel, markiert, auf dessen Kuppel Sterne gemalt sind. Die Symmetrie und Geometrie des Aufbaus der idealen Stadt Christianapolis (1619) von Johann Valentin Andreae sollten ein geordnetes Leben von 400 Stadtbewohnern gewährleisten..$^{10}$

In den modernen Utopien kreuzen sich die reale und die ideale Welt, es sind Revolutionen, mit deren Hilfe man sich erhofft, die Gesellschaft verbessern zu können. Neue Utopien können mit fernen Planeten oder mit der Idealisierung von historischen Gesellschaften verbunden sein. Eine utopische Denkweise hat man als Träger von neuen, radikalen Gedanken eingesetzt, wovon heutzutage die ökologischen und feministischen Utopien zeugen; die unterdrückten Minderheiten begünstigen sowie eine neue und bessere Gesellschaftsordnung. Die Elemente des utopischen Bewusstseins sind als Vorahnung von unentdeckten Welterscheinungen wahrzunehmen, nicht zu schweigen von den Erwartungen des noch unentdeckten Raumes und der Zeit. Die Utopie kann weiterhin als eine soziale Kritik betrachtet werden, indem sie sich durch eine Ignorierung des herrschenden Wertesystems äußert. Als Folge dessen wird die Vergangenheit entdeckt und ihr eine neue Bedeutung und ein neuer Wert verliehen. ${ }^{11}$

8 Thomas More, Utoopia, Loomingu Raamatukogu, 11/12 (2002).

9 Francis Bacon fasste im 17. Jahrhundert die Prinzipien der aufgeklärten Welt, in welcher ein wissenschaftlicher Geist herrscht, in Worte (The New Atlantis, 1623), auf Estnisch Francis Bacon, Uus Atlantis. Valik esseid, übersetzt von Karin Suursalu, bearbeitet von Terje Kuusik (Tallinn: Perioodika, 2004).

10 Ruth Eaton, Ideal Cities: Utopianism and the (Un) Built Environment (London: Thames \& Hudson, 2002), 70.

11 Leonidas Donskis, „Ideoloogia ja utoopia. Kas utopismi lõpp?“, Akadeemia, 10 (1995), 2151-2156; Sarapik, ”_topias and Islands“, 111-112. 

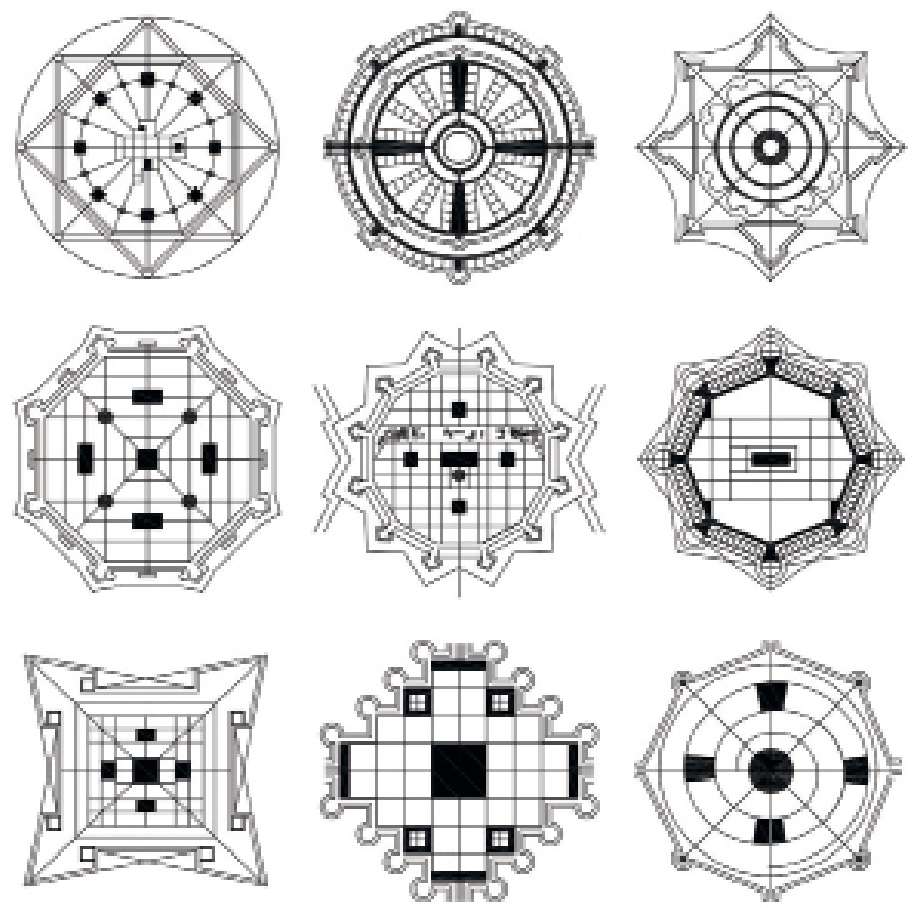

Abb. 1. Schemata der idealen Stadt des Zeitalters der Renaissance: 1. Filarete, 2. Fra Giocondo, 3. Girolamo Maggi, 4. Giorgio Vasari, 5. Antonio Lupicini, 6. Daniele Barbaro, 7. Pietro Cattaneo, 8/9 Francesco di Giorgio Martini. Zeichnungen zusammengestellt von Tuuli Org

\section{DIE IDEALSTÄDTE AUS DER ZEIT DER RENAISSANCE}

Die Idealstädte nahmen ihren Anfang von der utopischen Überzeugung, dass eine geometrische und symbolische Ordnung das ideale Funktionieren einer Stadt gewährleistet, was mit der harmonischen Ordnung des Universums in Verbindung gebracht wurde. Seit der Renaissance hat man die Städte als ganzheitliche Kunstwerke behandelt, was sich zusätzlich zur Architektur auch in den Planungen äußerte. Die Grundlage der Pläne einer Idealstadt waren durch die Jahrhunderte die während der Renaissance zusammengestellten Diagramme oder vereinfachte Schemata gewesen, die später einen ikonischen Wert erlangten. Dort wurde eine komplizierte Idee zu einer abstrakten und kraftvollen visuellen Zeichnung umgewandelt (Abb. 1). 


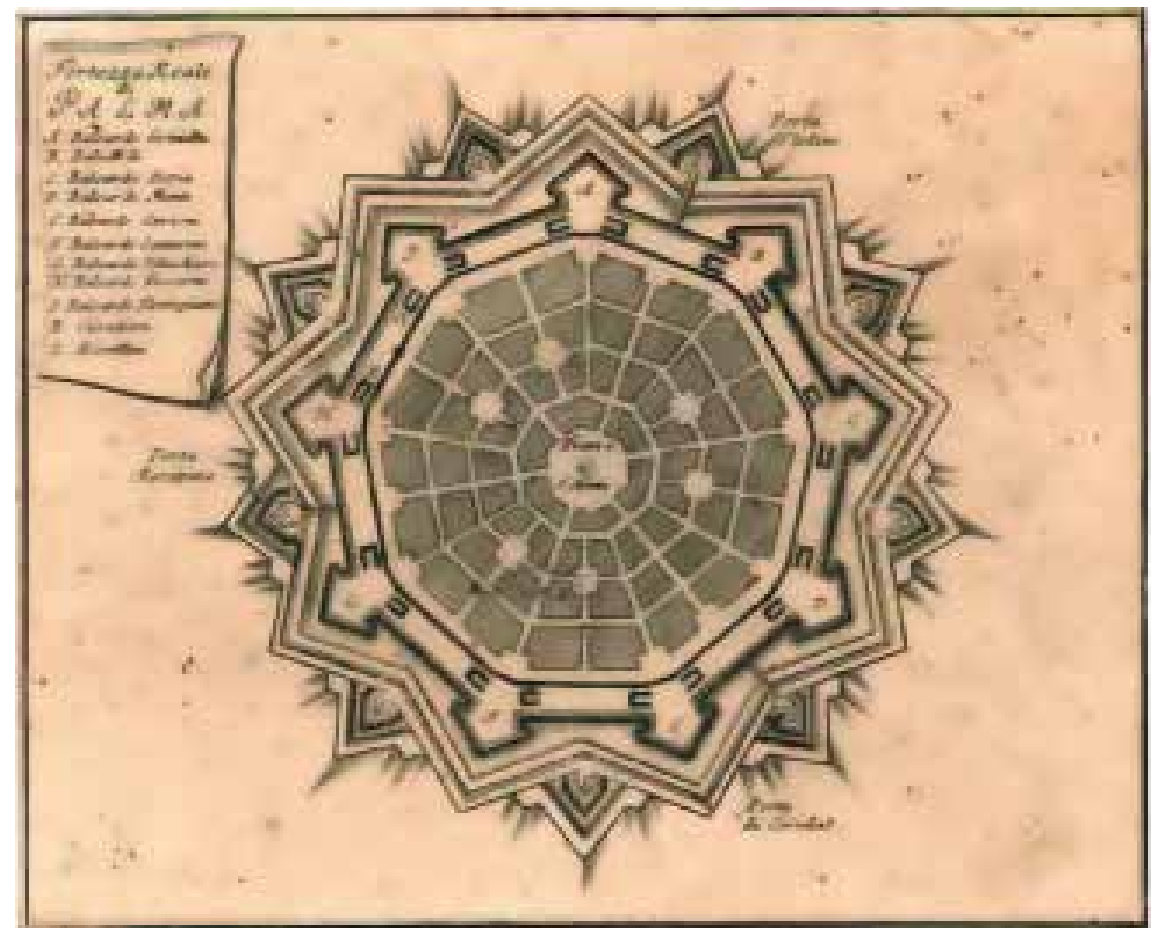

Abb. 2. Die befestigte Stadt Palmanova. KrA, 0406:15:065:001

Eines der ersten Beispiele des idealen Stadtschemas war die von Filarete (Antonio di Pietro Averlino) zusammengestellte, achteckige Idealstadt Sforzinda mit radialen Straßen (ca. 1464). Den Grund für die ideale Ordnung wiederspiegelnde Stadt mit geraden Straßen legte die Untersuchung von Leon Battista Albert, De re aedificatoria (1452-1485). Es folgten die quadrat- und kreisförmigen und die polygonalen Schemata der Idealstadt und der Befestigungsanlagen von Fra Giocondo, Albrecht Dürer, Francesco di Giorgio Martini, Vincenzo Scamozzi u.a. Einige der wenigen Städte, die nach dem Plan einer Idealstadt gebaut wurden und bis heute erhalten geblieben sind, sind die am Ende des 16. Jahrhunderts entworfene Stadt Palmanova in Italien (Vincenzo Scamozzi, 1593, Abb. 2) und Freudenstadt in Deutschland (Heinrich Schickhardt, 1599) sowie von den Städten des 17. Jahrhunderts Neuf-Brisach in Frankreich (Sébastien Le Prestre de Vauban, 1699-1702). ${ }^{12}$ 


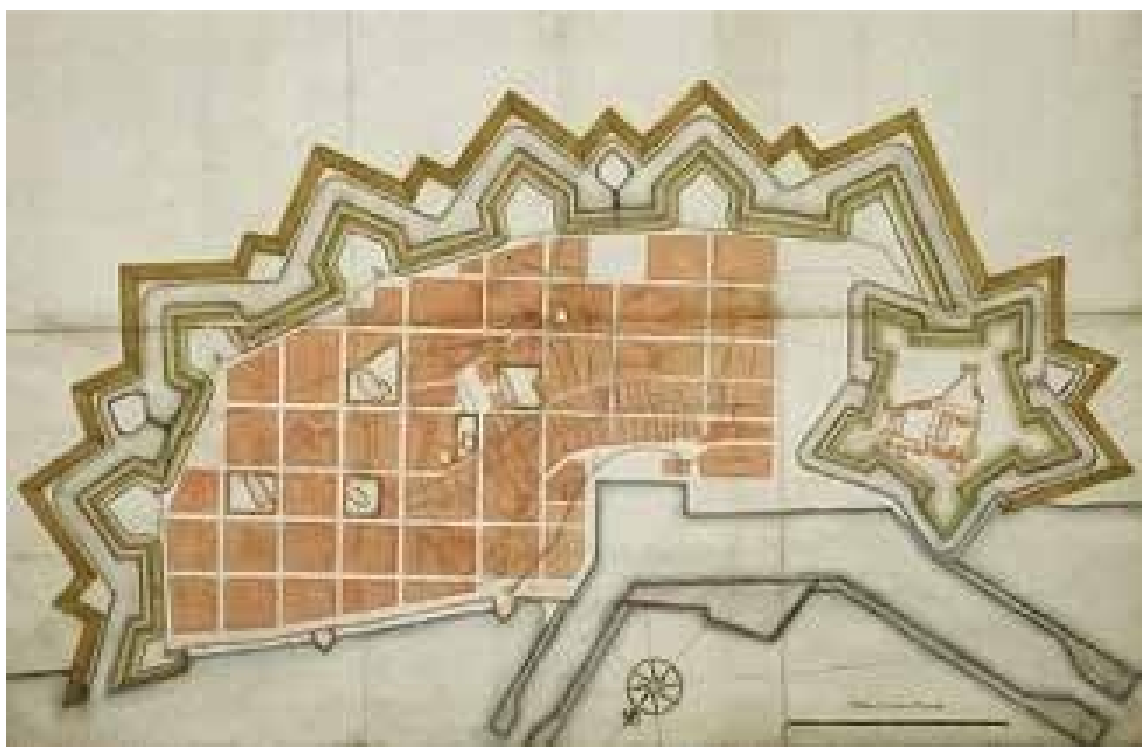

Abb. 3. Plan der Befestigungen und der Stadt Visby (1646). KrA, 0424:180:001a

Die Anlage von Städten mit einer regelmäßigen Planung wird gewöhnlich mit Eroberungen und großen Imperien in Zusammenhang gebracht. Das Schwedische Imperium war einer der wenigen Staaten Europas, wo im 17. Jahrhundert in großer Anzahl neue Idealstädte entworfen und gebaut wurden. Ein königliches Gesetz des Schwedischen Reichs aus dem Jahre 1628 hatte verordnet, dass ,,alle vorhandenen Städte durch regelmäßige Planungen umgestaltet werden müssen, um sie in eine bessere Ordnung zu versetzen, und alle alten Städte müssen in die gleiche Form gegossen werden". Auf dem heutigen Gebiet Schwedens wurden 30 neue Städte angelegt, 15 wurden verlegt, geplant war es, sämtliche alten Städte zu erneuern. In den Gebieten, die unter der Kontrolle des Reichs standen wie die baltischen Provinzen oder Finnland, wurden Erneuerungen in 450 Ortschaften geplant und über 600 Pläne entworfen. Die Mehrzahl dieser Planungen, die sich als Utopien erwiesen, wurde nicht in die Realität umgesetzt oder die Projekte wurden abgebrochen. ${ }^{13}$

Ein Beispiel der utopischen Art und Weise der Planung, die im Schwedischen Reich verbreitet war, stellt die Planung der Stadt Visby

13 Nils Ahlberg, Stadsgrundningar och planförändringar. Svensk stadsplanering 1521-1721 (Uppsala: Institutionen för landskapsplanering Ultuna, 2005), 372-373. 
aus dem Jahre 1646 dar (Abb. 3), wobei vorgesehen war, das mittelalterliche Straßennetz im gesamten Umfang durch ein rechteckiges Straßenschema und die alte Stadtmauer durch einen Befestigungsgürtel neuer Art zu ersetzen.

In Finnland waren bis zum Jahre 1653 aufgrund der Planungen 28 Städte gebaut oder erneuert worden. Die ersten von ihnen berücksichtigten noch in Anbetracht der Landschaft die mittelalterlichen Traditionen: Uusikaupunki/Nystad (1617), Uusikaarlepyy/Nykarleby (1620), Kokkola/ Karleby (1620) sowie Tornio/Torneå (1621). Der endgültige Durchbruch solcher Pläne, wo die Straßen ein Quadratmuster bilden, fand in den vierziger Jahren des 17. Jahrhunderts statt, als die Städteplanung von Per (Pietari) Brahe (dem Jüngeren) geleitet wurde. In der Planung der Stadt Turu/Åbo (1639, Anders Torstensson) wurde die mittelalterliche Stadt erhalten und der neue Stadtteil wurde auf der anderen Seite des Flusses errichtet. Bei der Planung der Städte Pori/Björneborg (1642, Torstensson) und Raahe/Brahestad (1650, Claes Claesson) wurde mechanisch der Quadratmusterplan eingesetzt, ohne Rücksicht auf das Relief der Landschaft zu nehmen. ${ }^{14}$

Während diese Periode in Schweden deutliche Spuren bei den mittelalterlichen Stadtkernen hinterließ, beschränkte sich die Erneuerung in Estland nur auf die Befestigung und Modernisierung der Festungen strategisch wichtigerer Städte - Reval (estnisch: Tallinn), Narwa (Narva), Dorpat (Tartu), Pernau (Pärnu) und Arensburg auf der Insel Ösel (Kuressaare auf Saaremaa). Die Autoren der neuen Pläne, Nicodemus Tessin, Georg von Schwengell und Erik Dahlberg, hatten die Planung von Städten und Befestigungsanlagen in Italien und in den Niederlanden studiert, was vor allem bei ihren ersten utopischeren Plänen, die sich auf die Theorie stützten, sichtbar wird. Das charakteristischste Beispiel ist der Plan für Arensburg von Nicodemus Tessin ${ }^{15}$ (Abb. 4), der den Wunsch Magnus De la Gardies, die Stadt, bei der sich bis dahin eine unregelmäßige Planung herausgebildet hatte, durch eine neue Idealstadt zu ersetzen, zum Ausdruck brachte. Es handelte sich ganz eindeutig um eine utopische Idee, die man noch nicht einmal versuchte umzusetzen. Den Plan der Idealstadt Arensburg aus dem Jahre 1652 von Nicodemus

14 Henrik Lilius, „Suurvalta-ajan kaupunkinrakentaminen 1617-1721“, Suomen kaupunkilaitoksen historia 1. Keskiajalta 1870-luvulle, herausgegeben von Päiviö Tommila (Helsinki: Suomen kaupunkiliito, 1981), 305-312.

15 Titellos [Arensburg], 1652, Krigsarkivet (Schwedisches Kriegsarchiv, KrA), 0406:28:002:005. 


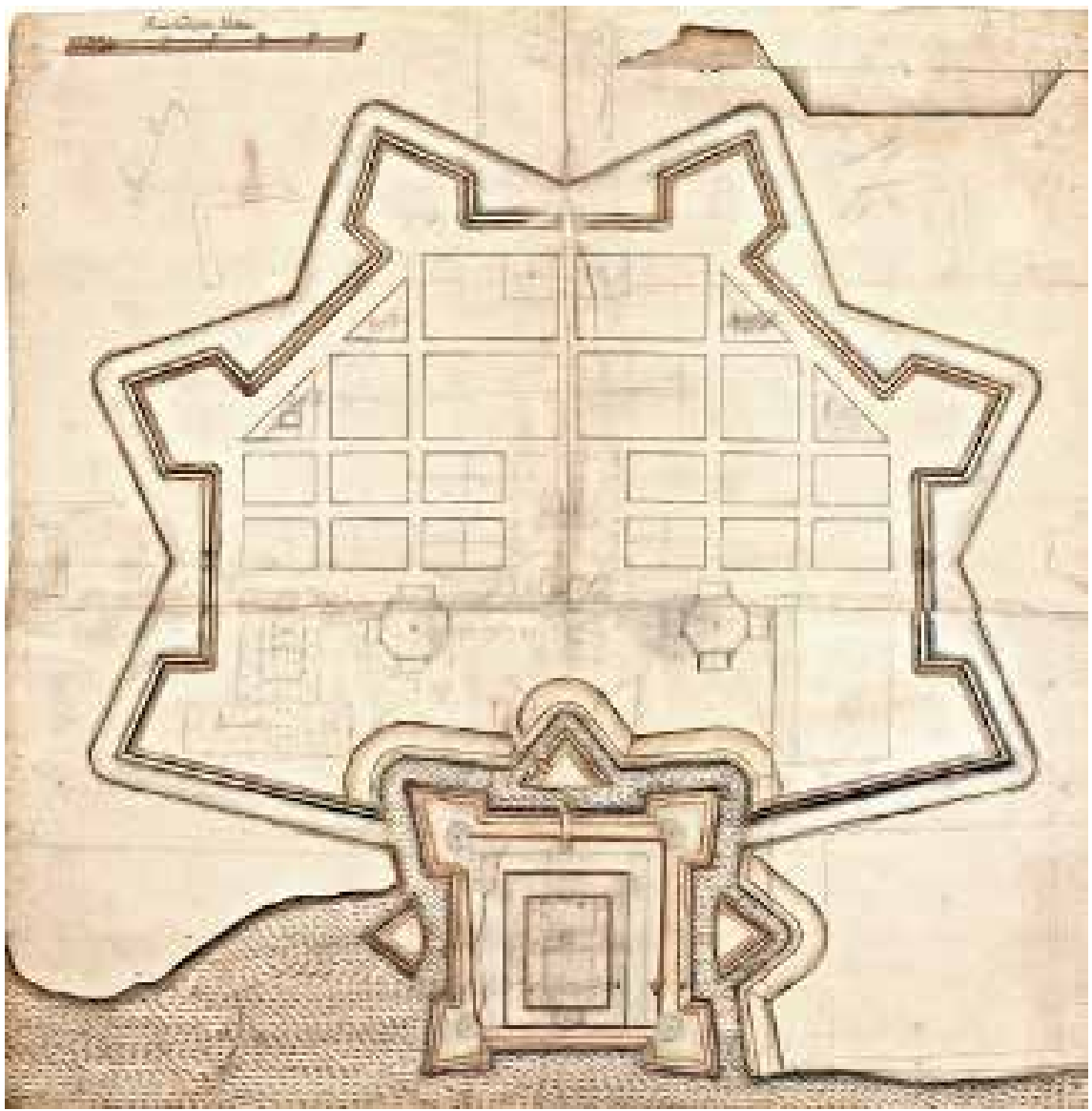

Abb. 4. Nicodemus Tessin der Ältere. Plan der Stadt Arensburg (Kuressaare) als ideale Stadt (1652). KrA, 0406:28:002:005

Tessin hat man mit der Planung von Landskrona in Schonen, die vom gleichen Autor im Jahre 1659 zusammengestellt wurde, verglichen. ${ }^{16}$ Dem Plan der Idealstadt Arensburg ähnelt auch der von Erik Dahlberg entworfene Plan von Landskrona aus dem Jahre $1680^{17}$ (Abb. 5), der oftmals als Beispiel für eine ganzheitliche Planung, welche das Schema der befestigten Idealstadt befolgt, angeführt wird. In keiner der beiden Städte wurden die utopischen Pläne einer Idealstadt realisiert.

16 Gerhard Eimer, Die Stadtplanung im schwedischen Ostseereich 1600-1715. Mit Beiträgen zur Geschichte der Idealstadt (Stockholm: Svenska Bokförlaget, 1961), 345.

17 Landskrona Fortifikationen, 1680, KrA: 0424:084:112b. 


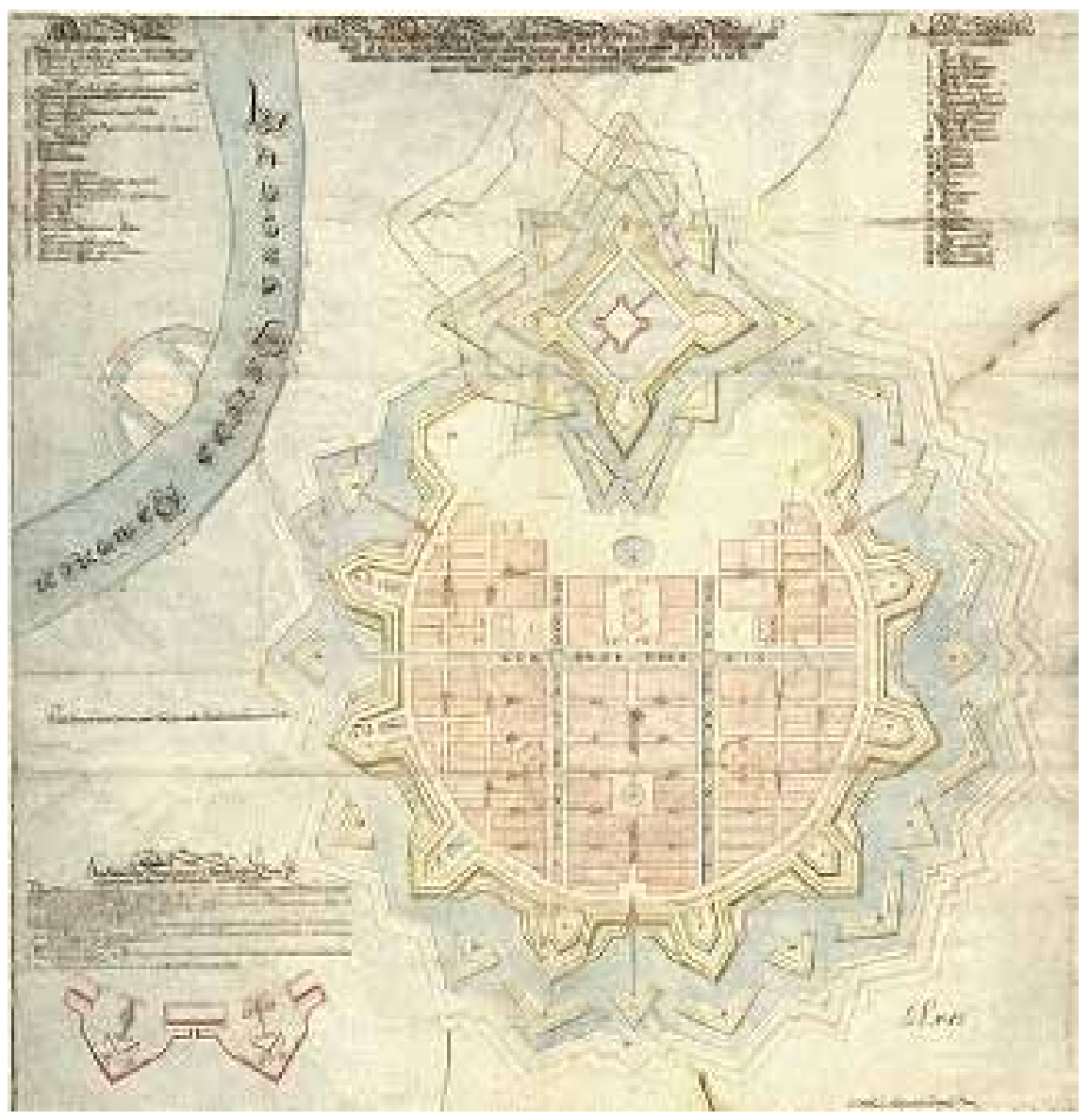

Abb. 5. Erik Dahlberg. Plan der Befestigungen der Stadt Landskrona (1680). KrA, 0424:084:112b

Narwa verfügt über mehrere Berührungspunkte mit Landskrona. In beiden Städten hat Erik Dahlberg Planungen der Stadt und der Befestigungen durchgeführt, der nach seiner Arbeit in Landskrona nach Estland kam. Bei beiden handelte es sich um militärisch wichtige Grenzstädte, die an einem Gewässer lagen. Dies rief den Bedarf nach einer stärkeren Befestigung hervor, wurde aber auch zum Grund dafür, dass die Städte wiederholt zerstört wurden. Die Jahre von 1581 bis 1704, als Narwa unter der Herrschaft Schwedens stand, werden für das 


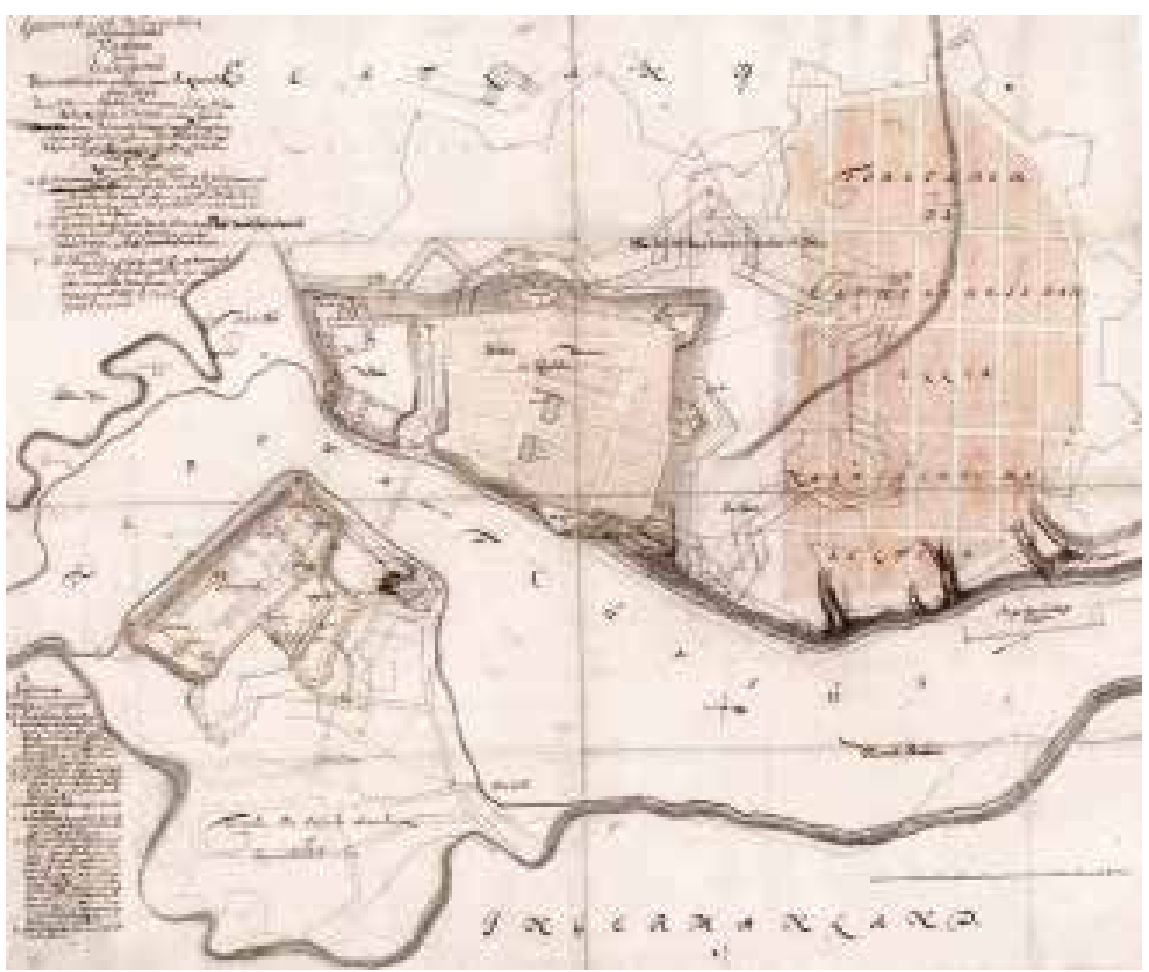

Abb. 6. Erik Dahlberg. Plan der Stadt Narwa (Narva) (1681). KrA, 0406:28:031:014

"Goldene Zeitalter" der Stadt gehalten - geplant war, Narwa in die zweite Residenz der Staatsmacht Schwedens zu verwandeln. ${ }^{18}$

Nach der Einnahme von Narwa durch die Schweden wurden innerhalb der folgenden vierzig Jahre mehrere Pläne zur Erweiterung der Stadt und zum Anlage von neuen Bastionen, welche die Stadt umgeben sollten, zusammengestellt. $\mathrm{Zu}$ den ambitioniertesten von ihnen werden der Plan Georg von Schwengells aus dem Jahre $1645^{19}$ und der Plan Johan von Rodenburgs aus dem Jahre $1647^{20}$ gezählt, die zwar die mittelalterliche Stadt bewahrten, aber vorsahen, dass man daneben einen um das Mehrfache größeren Stadtteil mit einem Quadratmusterplan errichten sollte, der durch eine Schutzmauer umgeben worden wäre. In

18 Sten Karling, Narva. Eine baugeschichtliche Untersuchung (Stockholm: Wahlström \& Widstrand, 1936), 35 .

19 Vorzeichnis und inhalt dieser Narwischen Planten [---],1645, KrA, 0406:28:031:001a.

20 Narva Verzeuchniis Narva Auch Iwannograd Nebst Dii Nergewarschen Anno 1647 Den 29 october, KrA, 0406:28:031:003. 


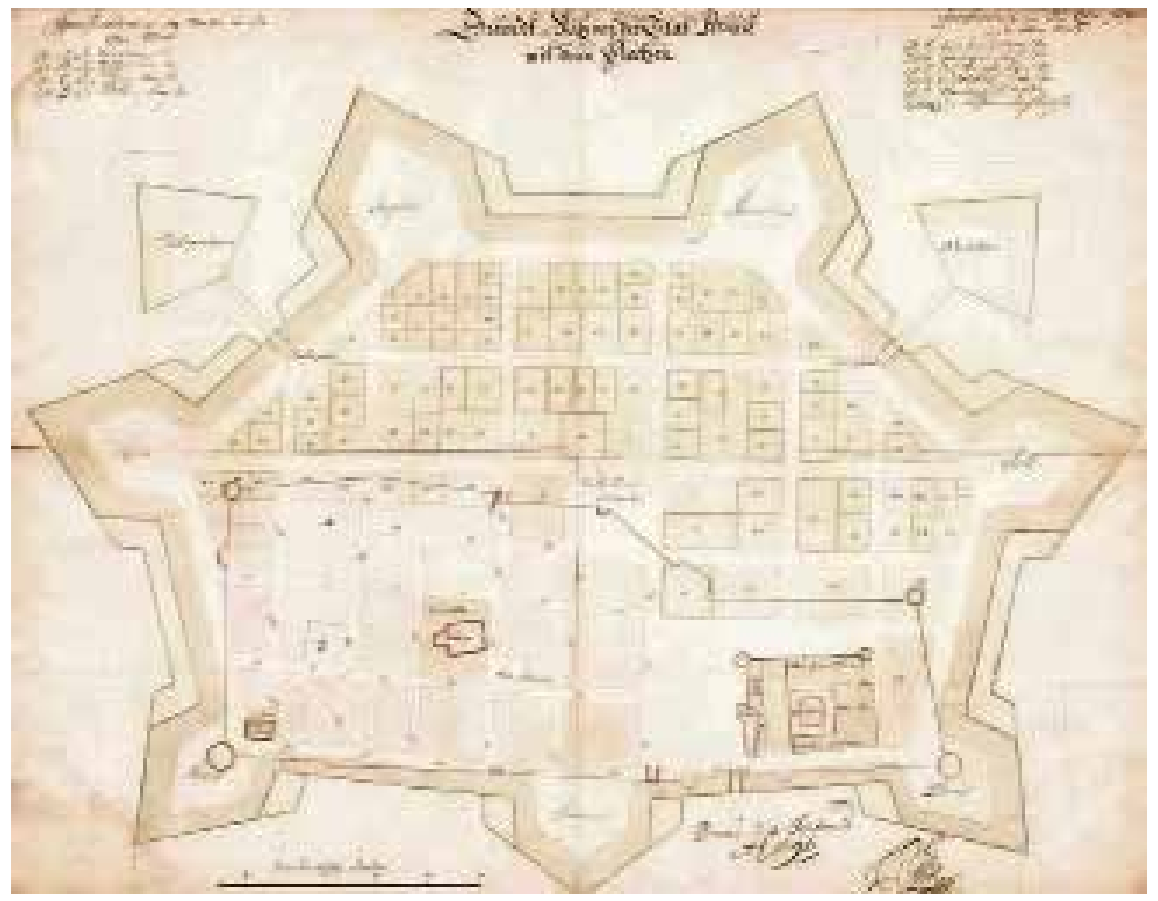

Abb. 7. Paul von Essen. Plan der Stadt Pernau (Pärnu) (1696). KrA, 0406:28:039:014

der zweiten Hälfte des 17. Jahrhunderts wurden für Narwa unter der Leitung von Erik Dahlberg mehrere Stadtbefestigungspläne entworfen, die auf dem neuen System der Verteidigung von Sébastien Le Prestre de Vauban basierten. Auf dem Diskussionsplan des Jahres $1681^{21}$ wurden gemeinsam die früheren Versionen und die neuen Möglichkeiten zur Erweiterung der Stadt vorgelegt. Zur Grundlage der Modernisierung der Stadtbefestigungen von Narwa wurde schließlich der Plan Erik Dahlbergs aus dem Jahre $1686^{22}$ (Abb. 6), auf dem der mittelalterliche Stadtteil und die neuen Stadtviertel im Norden und im Westen mit Straßen, die sich rechteckig kreuzen, durch unterschiedliche Farbtöne gekennzeichnet sind. Dabei hat man versucht, die Ausrichtungen der neuen Straßen mit denen der alten $\mathrm{zu}$ verbinden.

21 Narva Geometrisch Delineation Opå Staden och Slottet Narfwen sambt Ivanogorod, Uthi det tillståndh som det befans wara In November Anno 1681., KrA, 0406:28:031:014.

22 Narva Plan Utaf Staden och Fästningen Narfwen, 1686, KrA, 0406:28:031:022a. 
Aufgrund der Pläne des 17. Jahrhunderts kann man Schlüsse über die mittelalterliche Stadt Pernau ziehen, denn auf den meisten der Plänen, welche die Schweden zur Erneuerung der Befestigung und der Stadt entworfen haben, ist auch eine frühere Abbildung der Stadt dargestellt. Die deutlichsten Informationen über den alten und den neuen Stadtteil liefert der von Paul von Essen auf der Grundlage des Planes des Jahres 1667 zusammengestellte Plan von Pernau aus dem Jahre $1696^{23}$ (Abb. 7), auf dem die alte Stadtmauer, die Nikolaikirche, der Marktplatz und die Gebäude der Befestigungsanlagen gekennzeichnet sind, das mittelalterliche regelmäßige Straßennetz und die Platzierung der Stadtviertel und der südöstlich davon geplante Quadratmusterplan mit geraden Straßen und rechteckigen Grundstücken, die von einer Befestigungsanlage aus Erde mit sieben Bastionen umgeben sind, können deutlich unterschieden werden. Zwischen der Neustadt und der Altstadt war anstelle der alten Stadtmauer eine gerade Hauptstraße geplant und daneben im Zentrum der Stadt ein neuer rechteckiger Hauptplatz. Das eben Angeführte kann zu einem der hervorragenden Beispiel der Stadtplanung aus der schwedischen Zeit gezählt werden, welche die Planungsprinzipien einer Idealstadt befolgt und bei der die komplizierte Aufgabe gelöst worden ist, das Neue und das Alte miteinander zu verbinden und eine Ganzheitlichkeit mit einer symmetrischen Komposition, die den Forderungen des Zeitalters entspricht, zu erschaffen.

Während man in Schweden und in Finnland die alten Städte im verhältnismäßig großen Umfang durch neue, regelmäßige Quadratmusterpläne ersetzte, wurden die mittelalterlichen Planungsstrukturen der estnischen Städte nicht wesentlich verändert. In der Wirklichkeit wurde von den realen Baumöglichkeiten ausgegangen, wovon besonderes deutlich die Stadtplanungen für Narwa und Pernau vom Ende des 17. Jahrhunderts zeugen, wo die neuen Straßen des Quadratmusterplanes mit dem Früheren verbunden sind.

\section{DIE STADT DER IDEALEN ORDNUNG AUS DER ZEIT DER AUFKLÄRUNG}

Die Idealstadt der Renaissance wurde zum Vorbild der Stadtplanung des Zeitalters der Aufklärung im 18. und 19. Jahrhundert. Sowohl die geo-

23 Pernau Grundt-Riss von der Stat Pernau mit deren Plätzen, 1696, KrA, 0406:28:039:014. 
metrischen Pläne der Renaissance als auch die späteren des Barocks und des Klassizismus sollten die Grundlage für das rationale Funktionieren der Stadt legen und die Voraussetzungen für die Entstehung einer idealen Gesellschaft schaffen.

Die Erneuerung der Städte wurde vom Essay „Über die Verschönerung von Paris" (Des Embellissements de Paris, 1749) Voltaires, eines der frühesten Ideologen der Ideen der Aufklärung, beeinflusst. Während die urbanen Ideen des Theoretikers der Reorganisation des Stadtraums, Pierre Patte, vom Bedarf der Verbesserung der sanitären und hygienischen Bedingungen und der Umgestaltung des Verkehrs ausgingen, sahen die Phantasien von Claude-Nicolas Ledoux im Städtebau zusätzlich noch ein Mittel zur Schaffung einer sozialen Ordnung. ${ }^{24}$

Ein Idealbild von den Ausrichtungen des Städtebaus des 18. Jahrhunderts lieferte die Planung des im 17. Jahrhundert errichteten, großzügigen barocken Schlossensembles von Versailles. Ähnliche Planungsverfahren, die der Symmetrie untergeordnet waren, wurden auch bei der Erneuerung der größeren Städte Europas eingesetzt, wo sich breite und gerade Straßen und Alleen strahlenförmig auf den zentralen kreisförmigen oder polygonalen Plätzen vereinigten, wie zum Beispiel die Friedrichstadt in Berlin (1691), der Hannover-Platz in London (1718-1720), der Place de la Concorde (deutsch: „Platz der Eintracht“) in Paris (1748), das Schlossensemble Amalienborg in Kopenhagen (1749) usw. Wegweisend für die Städteplanung des Zeitalters des Klassizismus fungierten Pierre Patte (Plan der Pariser Plätze, 1765), John Gwynn (Westminster in London, 1766) und Claude-Nicolas Ledoux (Plan der Idealstadt Chaux, 1775). Zu den bekannteren Städten, die nach einer klassizistischen Stadtplanung gebaut wurden, zählten New Town in Edinburgh (James Craig, 1766) und Karlsruhe (1715), wo vom Schloss aus, das im Zentrum der Stadt errichtet wurde, 32 Straßen wie Sonnenstrahlen ausgingen - eine Stadt wie ein Stern -, klar und deutlich wie eine Regel. Aber zusätzlich dazu stand die Erneuerung der Städte durch königliche Schlösser und Monumente der Herrscher, die im Zentrum der Plätze standen, eindeutig im Dienst von politischen Zielen, indem sie dem Absolutismus huldigte. ${ }^{25}$

24 Philippe Madec, Etienne-Louis Boullée (Basel, Boston, Berlin: Birkhauser Verlag, 1989), $108 \mathrm{ff}$. 25 John Summerson, Die Architektur des 18. Jahrhunderts (Stuttgart: Verlag Gerd Hatje, 1987), $149-167$. 


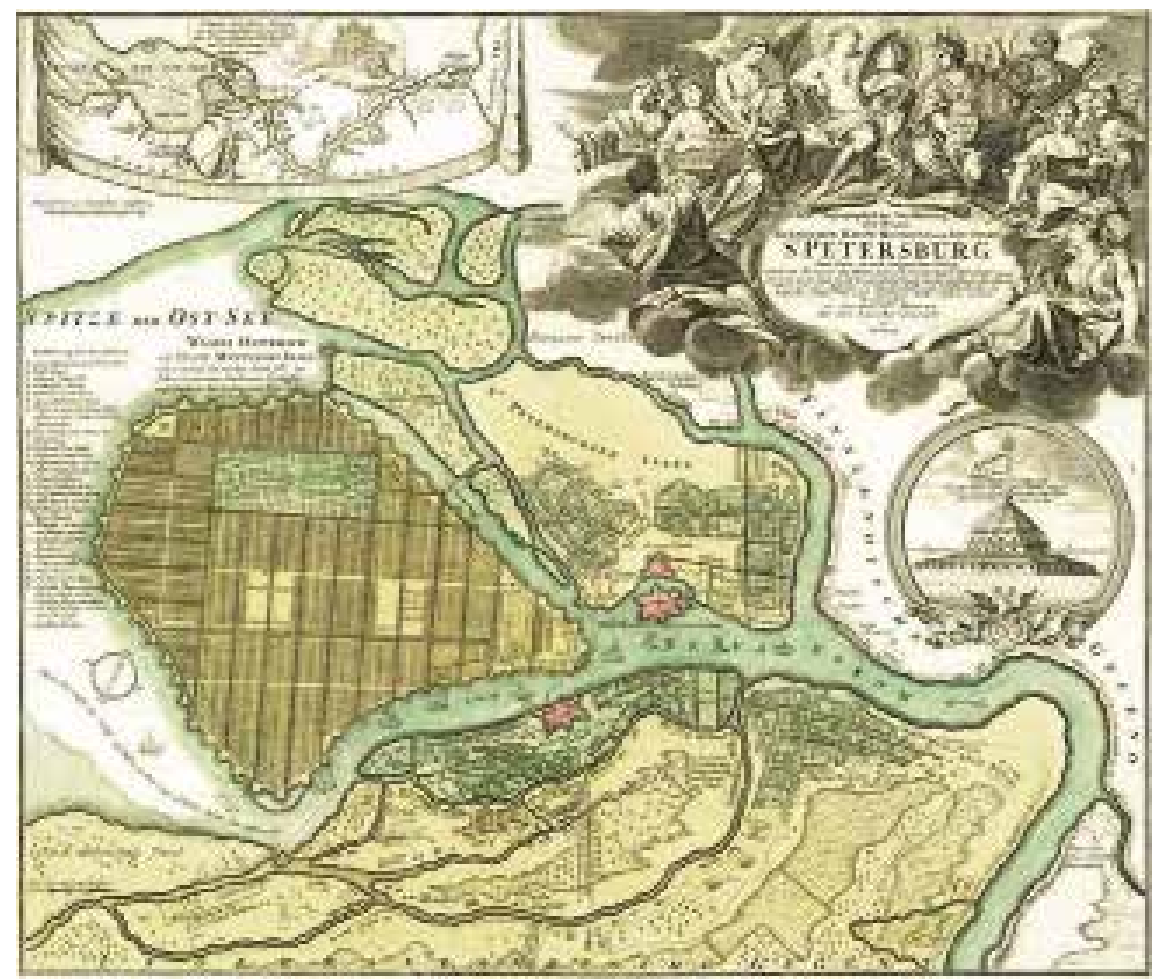

Abb. 8. Plan von St. Petersburg (1725). KrA, 0406:19:015:022 1 o

Zum Ziel der Umgestaltung des Stadtraumes während des Zeitalters der Aufklärung wurde vor allem die Verbesserung der Lebensbedingungen in den Städten, die erheblich angewachsen waren und über zu enge Straßen verfügten, aber im Städtebau sah man auch ein Mittel zur Erschaffung einer sozialen Ordnung. In der Mitte des 19. Jahrhunderts schuf dies die Voraussetzungen für die Entstehung der Stadt des neuen Zeitalters. In den alten Großstädten Europas wurden durch die vorhandenen unregelmäßigen Stadtviertel neue breite und radiale Alleen geplant, die sich auf geräumigen Plätzen zusammenzogen, wie zum Beispiel auf den Plänen der Erneuerung von Paris von Pierre Patte und Georges-Eugène Hausmann.

Solch eine Art und Weise der Planung, wo im Stadtraum die erzieherische Funktion der Ordnung, der Moral, der Hygiene und der Kontrolle gesehen wurde, ließ sich gut mit den ordnungsschaffenden Zielen des Russischen Reichs vereinbaren. In der zweiten Hälfte des 18. Jahrhunderts 
setzte in Russland eine umfangreiche Städteplanung ein. Während der Regierungszeit Katharina der Großen wurden von den 497 vorhanden gewesenen Städten die Pläne von 416 umgearbeitet. ${ }^{26}$ Zum Vorbild der neuen Ideen der Städteplanung im gesamten Russland wurde der Planungsprojekt der Vasil'evskij-Insel in St. Petersburg aus dem Jahre 1725 mit seinen kerzengeraden Stadtvierteln ${ }^{27}$ (Abb. 8).

Obwohl bei der Planung der größeren Städte kompliziertere geometrische Kompositionen eingesetzt wurden, verbreitete sich der von den Landvermessern zusammengestellte Quadratmusterplan mit einem vereinfachten Schema allgemein. Der Triumphzug der Quadratmusterpläne fing an, dies insbesondere in kolonisierten Ländern und in den Industrieund Garnisonsstädten. Solche Städte, die gezeichnet worden waren, als ob man eine Schablone eingesetzt hätte, treffen wir zahlreich an, angefangen vom amerikanischen Kontinent bis hin zu Skandinavien und auch in Estland handelt es sich um zwei Städte - Paldiski (historisch auf Schwedisch Rågervik und auf Deutsch Baltischport) und Võru (deutsch: Werro).

Baltischport (Rågervik) wurde 1715 unter der Führung Peters des Großen als Standort eines befestigten Hafens für die russische Kriegsflotte ausgewählt. Daneben wurde eine neue Siedlung nach einem Quadratmusterplan geplant, welche die dem Zeitalter charakteristische streng regelmäßige Planungsweise vertrat. ${ }^{28}$ In eine Garnisonsstadt, die als Kriegshafen angelegt wurde, und in das spätere Zentrum des Landkreises passte ein solcher Stadtplan, der Ordnung schuf, besonders gut hinein. Bis zur Mitte des 19. Jahrhunderts hatte Baltischport sich zu einer dicht bebauten Stadt entwickelt, wovon der Plan des Jahres $1850^{29}$ zeugt (Abb. 9). Die Städteplanung des Zeitalters vertritt in Estland auch die im Jahre 1784 gegründete neue Kreisstadt Werro und ihr Quadratmusterplan aus dem Jahre $1785^{30}$ (Abb. 10). Ähnlich zu

26 Sergej Ožegov, Tipovoe i povtornoe stroitel'stvo v Rossii v XVIII - XIX vekach (Moskau: Strojizdat, 1984), 66.

27 Ožegov, Tipovoe i povtornoe stroitel'stvo v Rossii, 26-30; Topographische Vorstellung der Neuen Russischen Haupt Residentz und See-Stadt St Petersburg samt ihrer zu erst aufgerichten Vestung, 1725, KrA, 0406:19:015:02210.

28 Titellos [Baltischport], 1767, KrA, 0406:28:003:001; der Stadtplan von Baltischport (Paldiski), erste Hälfte des 19. Jahrhunderts, Eesti Ajalooarhiiv (Estnisches Historisches Archiv, EAA), f. 2072, n. 2, s. 32. 29 Plan von der Stadt Baltischport, 1850 (schätzungsmäßig), erstellt von F. C. Meder und J. H. Schmidt, EAA, f. 2072, n. 2, s. 29.

30 Grund-Riss von der neuen Creis-Stadt Werro, 1785, zusammengestellt vom Landvermesser Carl von Bronsert. EAA, f. 909, n. 1, s. 131. 


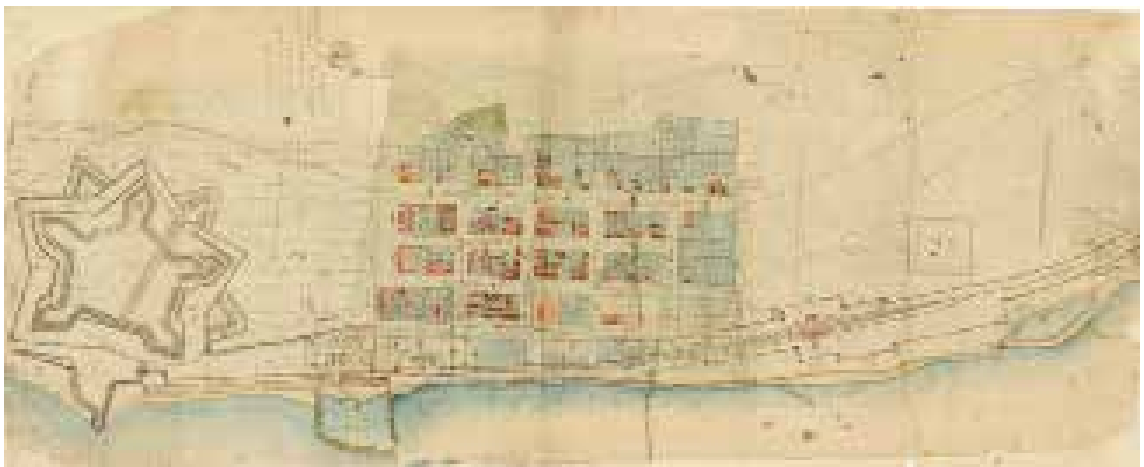

Abb. 9. Plan der Stadt Baltischport (Paldiski) (erste Hälfte des 19. Jahrhunderts). EAA, f. 2072 , n. 2, s. 32

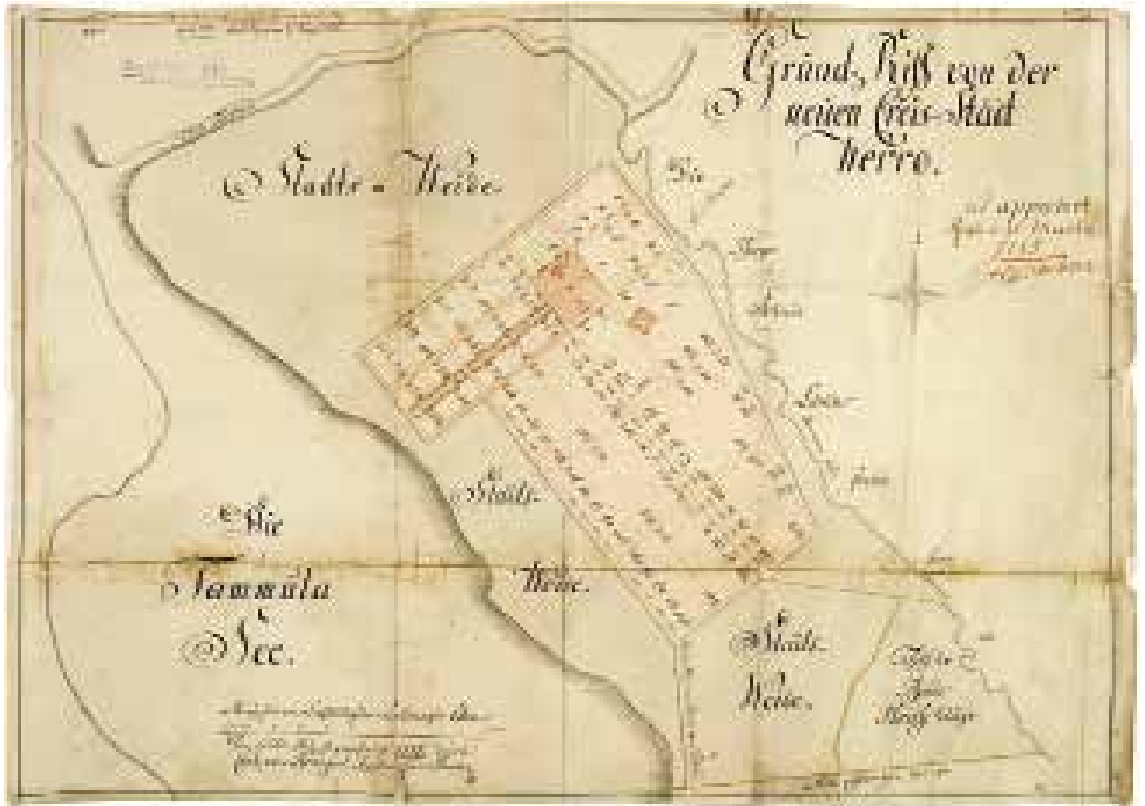

Abb. 10. Carl von Bronsert. Plan der Stadt Werro (Võru) (1785). EAA, EAA, f. 909, n. 1, s. 131

Paldiski hat sich auch in Võru das rechteckige Straßennetz bis heute erhalten, aber es ist nicht wirklich gelungen, die geplante Musterbebauung plangemäß zu errichten.

Noch weiter verbreitet war aber die Erneuerung der Städte durch Quadratmusterpläne. Als besonders utopisch erwies sich eine solche Planungsart bei historischen Städten, bei welchen es sich bei diesem 
Vorgehen im Regelfall als unmöglich herausstellte, das mittelalterliche unregelmäßige Straßennetz entsprechend dem neuen Plan auszubauen. Das Vereinheitlichungsprinzip, das den utopischen Idealen charakteristisch ist, wurde sogar trotz der verhältnismäßig langen Vorherrschaft des Russischen Imperiums in Estland nicht realisiert. Ein Grund hierfür war die Lage Estlands als Grenzland, dem neben den größeren Städten Russlands weniger Beachtung geschenkt wurde. Ausschlaggebender war aber die Tatsache, dass in Estland über Jahrhunderte die westlichen Werte, Traditionen und Mentalitäten geherrscht haben, die nicht durch die neuen Ideale, die über das Russische Reich das Land erreichten, wesentlich beeinflusst werden konnten. ${ }^{31}$

Die Regelmäßigkeit des Quadratmusterplans erforderte gar eine ähnliche unifizierte Bebauung, zu der die in Russland in den Jahren von 1809 bis 1812 herausgegebenen Musterfassaden wurden. Der Gedanke der Anwendung von Mustervorbildern trug eine breitere, dem Zeitalter der Aufklärung eigene Botschaft in sich. Durch die Architektur erhoffte man sich die Erlangung einer sittlichen und ästhetischen Übereinkunft in einer sozial differenzierten Gesellschaft. Es wurde angenommen, dass die staatlich festgesetzte Unifizierungspolitik im Stadtraum eine soziale Gleichheit hervorrufe, aber ideologisch handelte es sich um sozialutopische Ideen, denn die klassizistischen Musterfassaden, welche die scheinbare Gleichheit demonstrierten, stellten eher einen Teil des Kontrollmechanismus der zaristischen Staatsmacht dar. ${ }^{32}$

Obwohl sich im Klassizismus die Hoffnung auf etwas Neues und Besseres äußerte, besteht für den Kunsthistoriker Juhan Maiste ein Problem des Klassizismus in seiner Beziehung zur Macht. Er findet, dass die Manifestation dieses Stils am Hofe des Zaren, die Einschließung der Kunst im Reich der absoluten Wahrheit und der damit einhergehenden ausgewählten Formen kennzeichnet. ${ }^{33}$

Zusammenfassend kann man den Schluss ziehen, dass die Planungsweise, die der Ordnung und der Rationalität untergeordnet

31 Juhan Maiste, „Revolutionary Architecture in the East“, The Problem of Classical Ideal in the Art and Architecture of the Countries around the Baltic Sea: conference at the Estonian Academy of Arts, Nov. 9.-10. 2001, ed. by Krista Kodres, Piret Lindpere, Eva Näripea, Estonian Academy of Arts Proceedings, 13 (Tallinn, 2003), 209; Juhan Maiste, „The Glass Bead Game in the Topic of Classics: Baltic Identity and the Transport of Culture", Juhan Maiste, Tuldud teed edasi (Tallinn: [s.n.], 2007), 13, 20-25.

32 Epi Tohvri, Valgustusideede mõju Tartu arhitektuurikultuurile 19. sajandi alguses, Dissertationes Historiae Universitatis Tartuensis 18 (Tartu: Tartu Ülikooli Kirjastus, 2009), 207, 227.

33 Juhan Maiste, „Klassitsism ja tõde“, Kunstiteaduslikke Uurimusi, 1-2 (2008), 10-11; Juhan Maiste, „Klassika ja klassitsism“, Juhan Maiste, Tuldud teed edasi (Tallinn: [s.n.], 2007), 258. 
waren, und die Typisierung der Architektur wirkungsvoll den utopischen Ambitionen der Imperien diente - an die Stelle des Vergangenen einen mächtigen Staat mit geordneten Städten zu errichten.

\section{DIE TOTALE ERNEUERUNG DER STÄDTE IM 20. JAHRHUNDERT}

Am Anfang des 20. Jahrhunderts erschienen besonders deutlich neue Ideen des Städtebaus auf der Bildfläche, die mit den Ideologien von sowohl den Futuristen als auch der Diktatur einhergingen. Die feste Überzeugung der Futuristen bestand darin, dass eine neue Architektur nicht der historischen Kontinuität untergeordnet sein kann, und ihr Manifest trug die Botschaft weiter, dass jede Generation ihre eigene Stadt bauen solle. Aber um die neue Stadt bauen zu können, muss das bisherige Stadtnetz gesprengt werden - keine Restaurierung und keine Reproduktion der alten Statik war möglich. ${ }^{34}$

Dass man einen Schluss-Strich zum Vergangenen ziehen sollte, forderte auch Le Corbusier, der überzeugt war, dass die neue Zeit eine neue Stadt brauche, denn „eine krumme Straße ist der Weg des Esels, eine gerade aber die des Menschen und ein Rechteck stellt ein ausreichendes Werkzeug für die Arbeit dar". ${ }^{35}$ Für Le Corbusier war der Städtebau ein Resultat der Geometrie und der Funktionalität. Von ihm stammt auch der Gedanke, dass die neue Stadt die Konzentration der Ordnung und der Macht ist. Solche totalitaristischen Ansichten finden in der Städtebautheorie von Le Corbusier (Urbanisme, 1925) in den Verweisen auf Ludwig XIV., Napoleon, Hausmann u.a. eine Bekräftigung. ${ }^{36}$

Die vom Anfang des 20. Jahrhunderts stammenden Ideen von der Erneuerung der Städte wurden in Estland von der Planung von GroßReval/Groß-Tallinn von Elien Saarinen aus dem Jahre $1913^{37}$ (Abb. 11) vertreten, gemäß der sich an der Stelle der hölzernen Vorstädte ähnlich zu Paris, Riga und Helsinki bis zu sechsstöckige Stadthäuser aus Stein erhoben hätten. Das kolossale Projekt Saarinens blieb nur auf dem Papier,

34 Hanno-Walter Kruft, A History of Architectural Theory from Vitruvius to the Present (New York: Princeton Architectural Press, 1994), 403-405.

35 Kruft, A History of Architectural Theory, 400.

36 Kruft, A History of Architectural Theory, 399-401.

37 Eliel Saarinen, Suur-Tallinna planeering, 1913, Eesti Arhitektuurimuuseum (Estnisches Architekturmuseum, EAM), Archivdepot. 


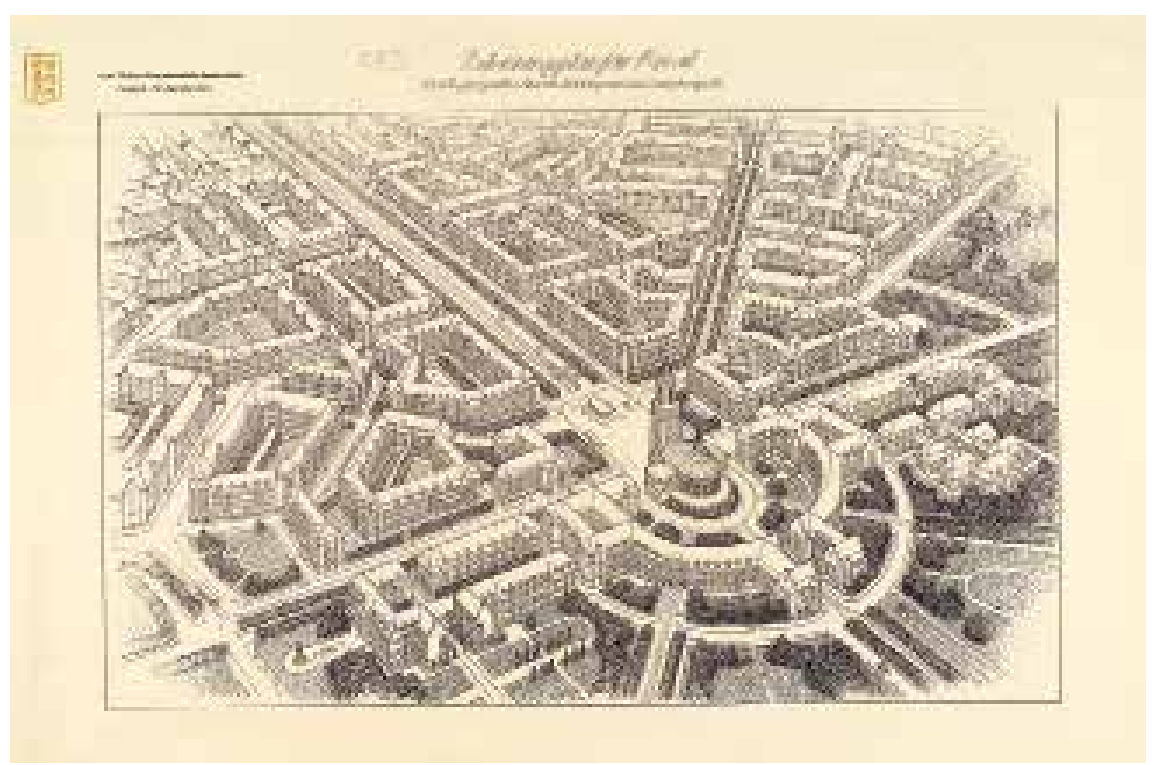

Abb. 11. Eliel Saarinen. Die Planung von Groß-Tallinn (1913). EAM

da der Erste Weltkrieg ausbrach und die politische Situation sich veränderte, aber sein Einfluss ist stellenweise bei den späteren Planungen für Tallinn bemerkbar. ${ }^{38}$

Der Anfang der einheitlichen Planung der Städte in der unabhängigen Republik Estland wird mit den dreißiger Jahren des 20. Jahrhunderts in Verbindung gebracht. Die neuen Baugesetze und Vorschriften ${ }^{39}$ spiegelten die Ideologie des jungen Staates wider - den Wunsch, seinem Volk selbst eine europäische Umgebung zum Arbeiten und zum Leben zu gestalten, was für ",ambitioniert totalitaristisch" gehalten worden ist. ${ }^{40}$ Am Vorbild von Hitler, Mussolini und Stalin legte sich auch das Staatsoberhaupt Estlands, Konstantin Päts, bei den Bau- und Architekturfragen ins Mittel, indem er im Jahre 1935 schrieb, dass es nicht möglich sei, einen Staat

38 Eugen Habermann hat viele Ideen Groß-Tallinns von Eliel Saarinen für seinen Generalplan Tallinns aus dem Jahre 1921 als Grundlage genommen.

39 Das durch ein Dekret von Konstantin Päts aus dem Jahre 1935 erlassene „Gesetz zur Änderung und Ergänzung des Baugesetzes“ legte das Recht der Regierung fest, die Organisierung des Aussehens der Tallinner Innenstadt in die Wege zu leiten. Mit dem „Gesetz zur Änderung des Baugesetzes“ aus dem Jahre 1937 wurde der Nationale Bauausschuss gebildet, dessen Leiter kein anderer als Konstantin Päts war (Karin Hallas-Murula, „Konstantin Pätsi Tallinn“, Sirp, 30.4.2004, nr 14).

40 Krista Kodres, „Sada aastat ehitamist Eestis. Ideid, probleeme ja lahendusi“, Ehituskunst, 24, 25, 26 (1999), 15. 
zu regieren, ohne dass die Gesellschaft gemäß einem festen Plan in Ordnung gebracht worden wäre. ${ }^{41}$

Wenn die Verneinung der Vergangenheit von Seiten der Avantgarde am Anfang des 20. Jahrhunderts absolut war, dann waren die Architektur und der Städtebau, die sowohl mit der faschistischen als auch der stalinistischen Ideologie einhergingen, auf die Antike hin orientiert. Die Architektur- und Städtebauideologie der autoritären Regime Europas stellten die Grundlage, auf die sich hinfort die Architekturund Städtebaupolitik der Sowjetunion stützte. Die avantgardistischen Richtungen der zwanziger Jahre des 20. Jahrhunderts gerieten insbesondere in Deutschland und in Russland in Ungnade Dort wurde unter den Bedingungen eines starken ideologischen Druckes im Laufe der dreißiger Jahre des 20. Jahrhunderts eine Monumentalarchitektur entwickelt wurde, welche die nationalen Werte und das klassische Erbe zur Synthese brachte..$^{42}$ Hannah Arendt, eine der einflussreichsten Theoretikerinnen der Theorie des Totalitarismus, hat die Terrorsysteme von Hitler und Stalin verglichen und Ähnlichkeiten in den Hintergründen und im Wesen dieser zweier Regime hervorgehoben. ${ }^{43}$

Was charakteristisch für die autoritären Regime war, die versuchen, sich durchzusetzen, so hat man sich auch in der Sowjetunion auf traditionellen Architektur- und Planungsverfahren gestützt, die in sich sowohl die klassischen als auch die nationalen Werte vereinigten. Boris Groys hat die Gegensätzlichkeit von dem „Traum-Realismus“, welcher dem Inhalt nach sozialistisch und der Form nach national sein sollte, als das „totale Kunstwerk Stalins“ analysiert. Das Erschaffen einer neuen sowjetischen Gesellschaft war zwar in die Zukunft gerichtet, aber auf der anderen Seite wurde es durch eine Liebe zur Klassik gekennzeichnet, was als ein Akt der Rettung von Kulturerbe interpretiert worden ist. ${ }^{44}$

In der Sowjetunion wurden als eines der Hauptmittel, um die Ideologie der Mächtigen unters Volk zu bringen, die Planung und die Architektur eingesetzt. Nach dem Zweiten Weltkrieg wurde neben dem Wiederaufbau der Ruinen, das Entwerfen der für die neue Gesellschaftsordnung passenden Zentren zu einem wichtigen Ziel. Da fast das gesamte Land dem

41 Karin Hallas-Murula, „Konstantin Päts - ehitaja“, Eesti Ekspress, 6.5.2004.

42 Hanno-Walter Kruft, Geschichte der Architekturtheorie. Von der Antike bis zur Gegenwart (München: C. H. Beck, 2004), 448-452; Faschistische Architekturen. Planen und Bauen in Europa, 1930 bis 1945, hrsg. von Hartmut Frank (Hamburg: Christians, 1985).

43 Ivi Masso, „Hannah Arendt. Totalitarismi põhjustest ja olemusest“, Vikerkaar, 8-9 (2001), 188.

44 Boris Groys, „Stalin-stiil“, Akadeemia, 3 (1998), 642. 


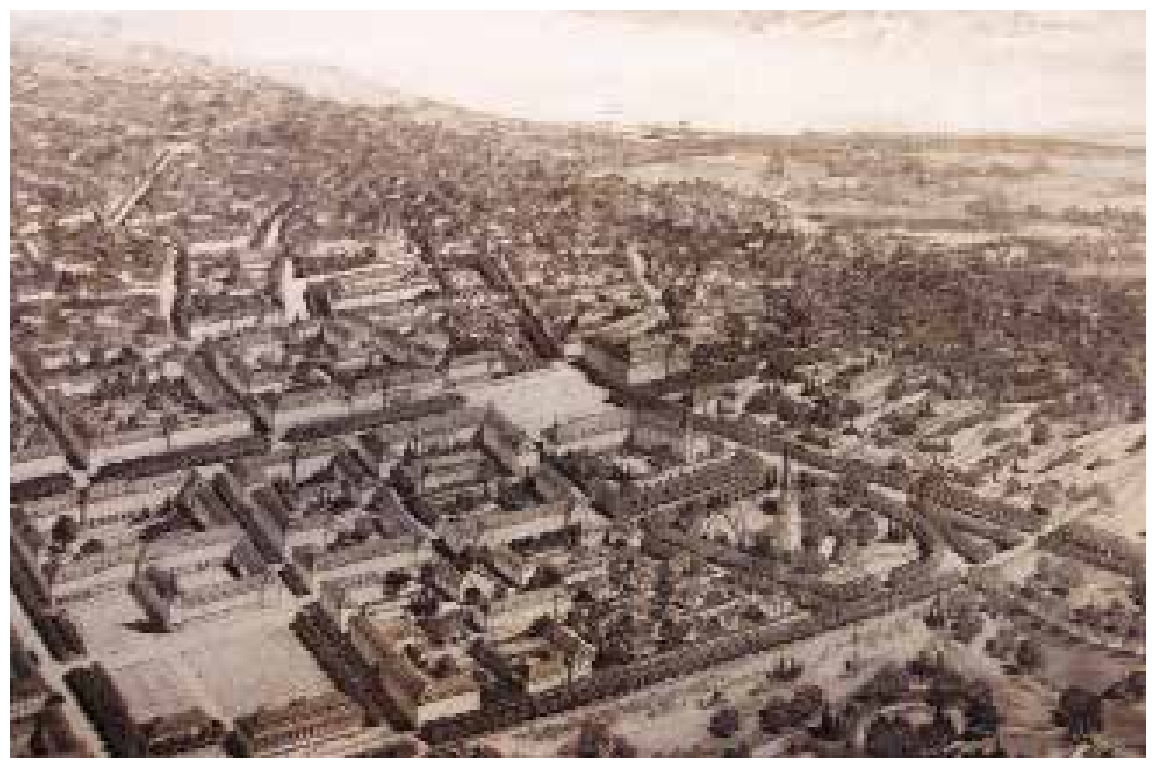

Abb. 12. Endel Laasi. Die Planung der Stadt Viljandi aus der Vogelperspektive (1948). EAM, f. 3 , n. 1 , s. 26

Staat gehörte, war es möglich, idealnahe Stadtpläne zu entwickeln, womit man eine totale Erneuerung der alten Städte und die Errichtung neuer Städte anstrebte. ${ }^{45}$

Die neuen Planungen der Städte basierten bis zur Mitte der fünfziger Jahre des 20. Jahrhunderts auf traditionellen Planungsprinzipien. Die Hauptachse der klassisch symmetrischen Planung stellten die überbreiten und kerzengeraden Alleen, von wo aus sich großzügige Ansichten auf die wie für Militärparaden ausgelegten Plätze und auf zentrale Monumente eröffneten. Das Platzensemble als das Symbol der Sowjetmacht musste ein repräsentatives kompositorisches Ganzes sein - die Städte wurden als großzügige räumliche Skulpturen entworfen.

Als charakteristische Beispiele für die Planung der Nachkriegszeit gelten die in den Jahren von 1945 bis 1947 erstellten Entwürfe für der Stadt Viljandi (deutsch: Fellin) von Ott Puuraid und Anton Soans, ${ }^{46}$ womit eine grundlegende Erneuerung der mittelalterlichen Altstadt geplant war (Abb. 12). Solche kardinalen Erneuerungspläne wurden für alle historischen Städte angelegt, aber ihre plangemäße Verwirklichung wurde

45 Lilian Hansar, Linnast muinsuskaitsealaks, 105-134.

46 EAM, f. 3, n. 1, s. 152; EAM, f. 3, n. 1, s. 199; EAM, f. 3, n. 1, s. 202. 


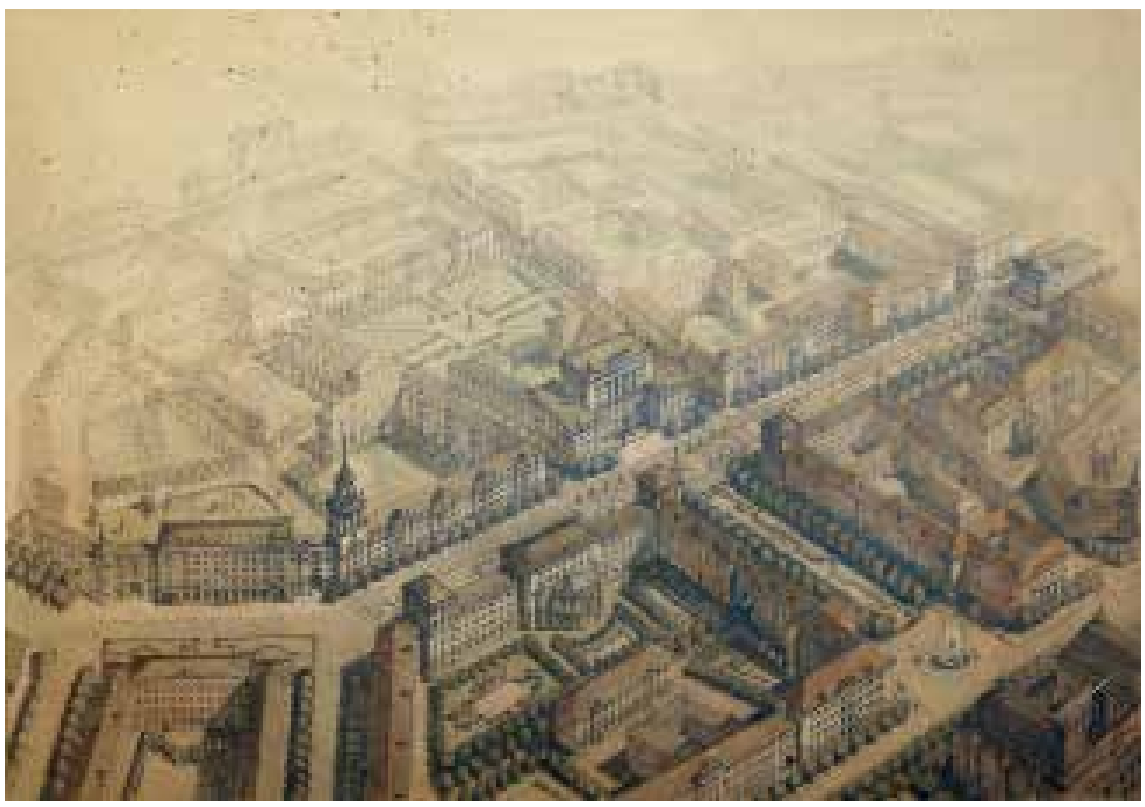

Abb. 13. Harald Arman. Die Planung des Kulturzentrums in Tallinn aus der Vogelperspektive (1951?). EAM, f. 3, n. 1, s. 32

bereits ein Dutzend Jahre später für irreal erklärt. Nur in vereinzelten Städten gelang es, einige Gebäudeensembles fertigzubauen, wie zum Beispiel der unter Anleitung von Harald Arman geplante Zentralplatz von Pärnu ${ }^{47}$ den man wegen seiner unpassenden Ausmaße als „ein Meisterwerk des stalinistischen Potemkinschen Dorfes" bezeichnet hat $^{48}$. Entsprechend der ursprünglichen Planung wurde das Projekt des Tallinner Kulturzentrums teilweise in die Wirklichkeit umgesetzt (Harald Arman, 1948) $)^{49}$ (Abb. 13), bei dem geplant war, die für die Stadt nötigen kulturellen Einrichtungen (das Theater, das Kunstmuseum, die Bibliothek, die Akademie der Wissenschaften u.a.) in einem Ensemble zu verbinden. ${ }^{50}$ In Tartu wurde an der Stelle, wo sich die Straßen Riia

47 Die Idee des Zentralplatzes von Harald Arman ist auf dem Generalplan der Stadt Pärnu aus dem Jahre 1953 fixiert (EAM, f. 3, n. 1, s. 468).

48 Mart Kalm, Eesti 20. sajandi arhitektuur (Tallinn: Prisma Prindi Kirjastus, 2001), 262.

49 EAM, f. 3, n. 1, s. 330; EAM, f. 3, n. 1, s. 164; EAM, f. 3, n. 1, s. 31; EAM, f. 3, n. 1, s. 31; EAM, f.

3, n. 1, s. 32 .

50 Mart Kalm, Eesti 20. sajandi arhitektuur, 246-249. 


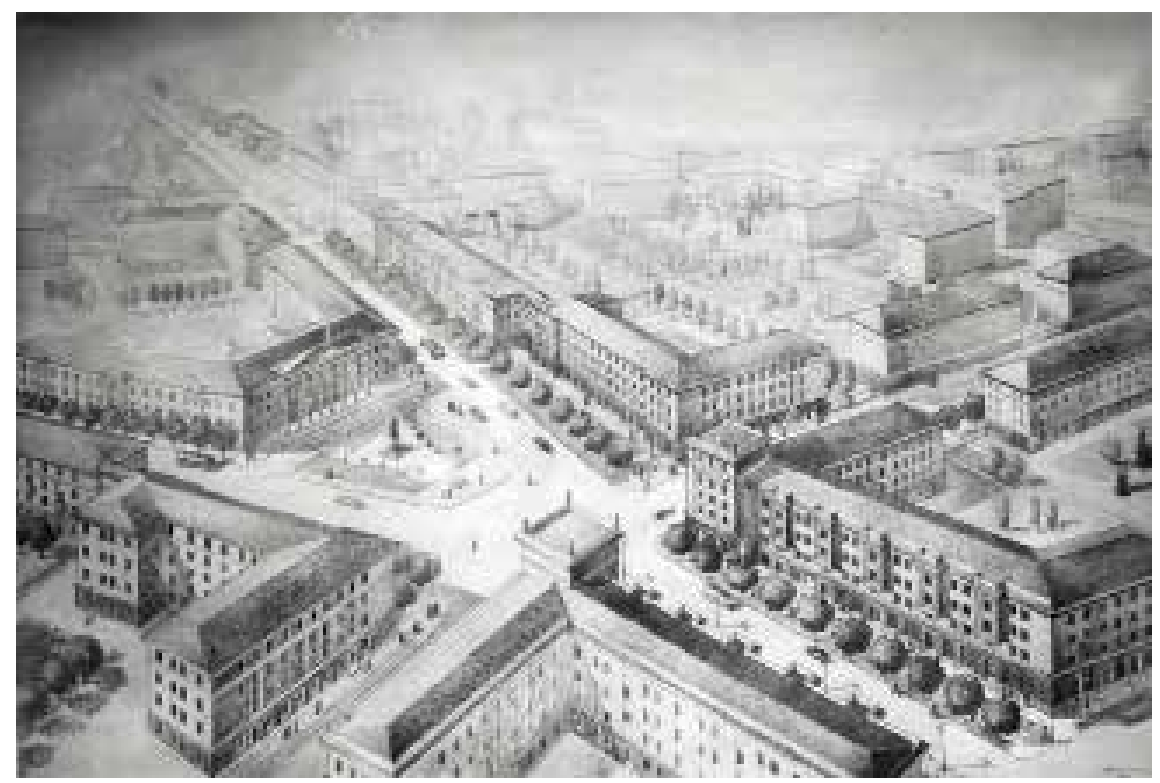

Abb. 14. Raul Kivi. Perspektivansicht des Lenin-Platzes in Tartu (1952). EAM

und Võru gabeln, der Leninplatz (Raul Kivi, 1952) $)^{51}($ Abb. 14) und eine ihn umsäumende gleichartige Bebauung geplant.

Obwohl der totale Umbau der vorhandenen Städte scheiterte, gelang es der Sowjetmacht, ihre Anwesenheit auf dem nordöstlichen Gebiet Estlands zu sichern, wohin man in den fünfziger Jahren des 20. Jahrhunderts mehrere neue Industriestädte wie Sillamäe, Kohtla-Järve, Jõhvi, Ahtme, Sompa u.a. baute. Wegen ihrer privilegierten Umstände konnte man dort die Architekturideale des Stalinismus luxuriöser und schneller als anderswo in die Tat umsetzen. Der Prozess der gewaltsamen Besetzung des Gebiets, das traditionell von den Esten besiedelt war, und der Russifizierung sowie die explosionsartige Entwicklung der Industriestädte sind als urbane Anomalie bezeichnet worden. ${ }^{52}$

51 Tartu, Lenini väljaku planeering ja perspektiivvaade 1952, zusammengestellt von Raul Kivi, siehe Raul-Levroit Kivi, Tartu planeerimisest ja arhitektuurist. Artikleid ja mälestusi (Tallinn: Eesti Arhitektuurimuuseum, 2005), 9.

52 David Vseviov, Kirde-Eesti urbaanse anomaalia kujunemine ning struktuur pärast Teist maailmasõda (Tallinn: Tallinna Pedagoogikaülikooli kirjastus, 2002), 35. 


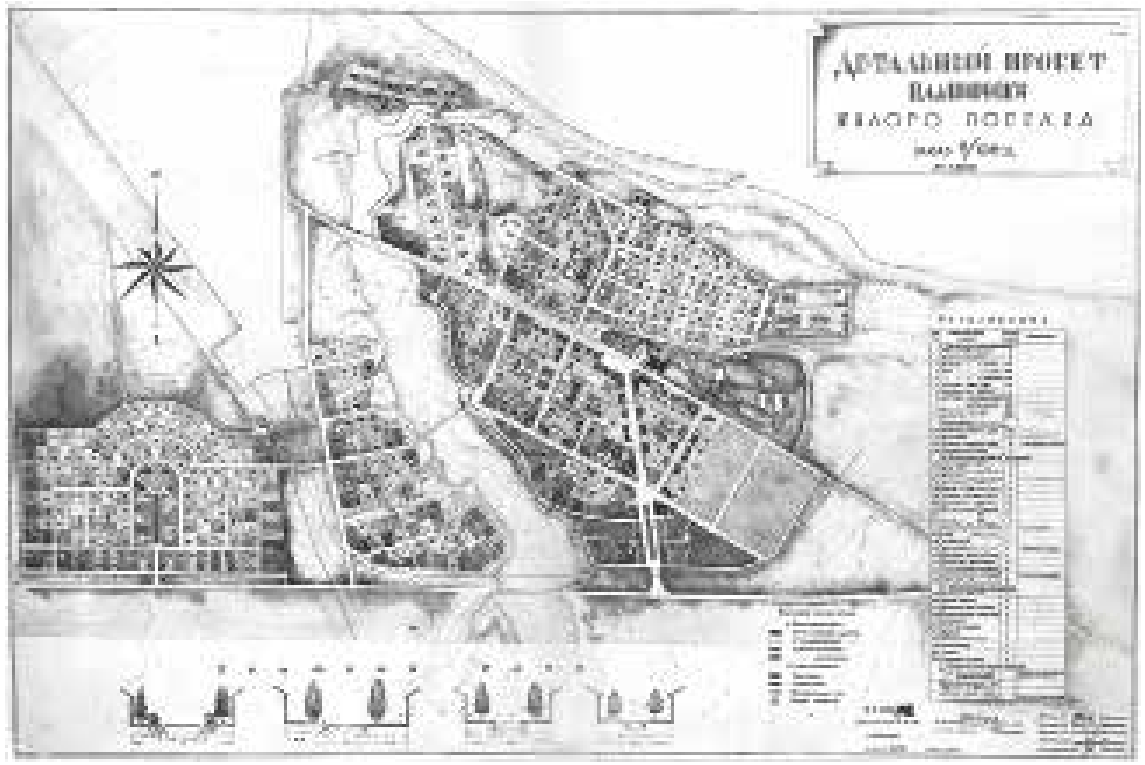

Abb. 15. A.F. Nikajev. Entwurf der Detailplanung für die Stadt Sillamäe (1947-1948). Sillamäe Museum, 2Ajd/0463

Zum Anlass der Gründung der Arbeitersiedlung von Sillamäe ${ }^{53}$ an der Stelle eines ehemaligen Gebiets der Sommerfrische wurde der Beginn des Baus einer Urananreicherungsanlage im Jahre 1946, welche der Verteidigungsindustrie der Sowjetunion dienen und atomwaffenfähiges Uran liefern sollte. Auf dem Generalplan der neuen Stadt aus den Jahren 1946 und 194754 (Abb. 15) war die Hauptstraße (Kesk tn, auf Deutsch Zentralstraße) an der Stelle der alten Narvaschen Landstraße geplant und der Park auf dem Gebiet des früheren Waldparks. Das Bebauungsensemble des Zentralplatzes, der sich auf der hohen Steilküste befand, wird von dem Plan und der Perspektivansicht des Zentralplatzes ${ }^{55}$ auf dem Entwurf des Bebauungsplans der Jahre 1947 und $1948^{56}$ illust-

53 Die Entscheidung über die Gründung der Arbeitersiedlung Sillamäe, die der Stadt Narva untergeordnet war, wurde per Gesetz des Präsidiums des Obersten Sowjets der Estnischen Sowjetrepublik vom 6. Januar 1949 getroffen Eesti Riigiaarhiiv (Estnisches Staatsarchiv, ERA), f. R-3, n. 3, s. 1071.

54 General'nyj proekt planirovki žilogo poselka, 1947 [Generalentwurf einer Einwohnersiedlung, 1947], Naučno issledovatelskij institut (NII) Nr. 9, Leningradskij filial, F. N. Djuženko (Architekt Künstler), A. F. Nikaev (leitender Architekt), Sillamäe Muuseum (Museum Sillamäe), SM2Ajd/0462. 55 Plan central'noj plošadi, 1948 [Plan des zentralen Platzes], A. F. Nikaev. Sillamäe Muuseum, SM2Ajd/0464.

56 Detal'nyj planirovki žilogo poselka, 1948 [Detaillierte Planung einer Wohnsiedlung, 1948 ], Gosudarstvennyj Special'nyj Proektnyj Institut (GSPI) Nr. 12, Leningradskij filial, I. V. Fabrikov (Hauptingenieur des Projektes), A. F. Nikaev (leitender Architekt), Sillamäe Muuseum, SM2Ajd/0463. 
riert, wo der Platz durch eine hohe Umzäunung vom Meer abgetrennt ist. Mit der Baunutzungsschablone der Straßenfassaden, die zu den Bestandteilen des Bebauungsplans gehörte, wurde vorgeschrieben, wie die Höhe, Breite, die Form der Dächer sowie die Gestaltung der Fassaden auszusehen hatten. Die vom Zentralplatz in Richtung auf das Meer hin absteigende breite Treppe und die vierreihige Allee mitsamt den hohen Wohnungsblocks, welche sie umrandeten, wurden erst mit dem Projekt der Stadtplanung aus dem Jahre $1949^{57}$ entworfen. Somit können in der kurzen Baugeschichte des Zentrums von Sillamäe zwei Perioden unterschieden werden, die vor allem in der Änderung der Höhe der Bebauung mit neoklassizistischer Architektur zum Ausdruck kommen, aber auch in der Öffnung des Zentralplatzes der Stadt in Richtung zum Meer, wohin man zwar spazieren konnte, wo aber kein Hafen vorhanden war und auch nicht geschwommen wurde. In Sillamäe kam man innerhalb von einigen Jahren dazu, 70 zwei- oder dreistöckige Häuser und 280 einstöckige Häuser, einen Krankenhauskomplex, mehrere Kindergärten, eine Mittelschule, das Kulturhaus, zwei Kinogebäude, das Gebäude des Exekutivkomitees der Stadt, eine Reihe von Geschäften und Garküchen zu bauen. ${ }^{58}$ Bis zum Anfang der fünfziger Jahre des 20. Jahrhunderts hatte Sillamäe sich zu einer einzigartigen Stadt für die Verhältnisse Estlands entwickelt, die eine stolze Bezeichnung trug - eine bestmöglich gestaltete Industriesiedlung städtischen Typs. Sillamäe ist ein Beispiel für eine städtische Utopie, die sich verwirklicht hat und die aber bis zum Ende der Sowjetzeit für die gewöhnlichen Bewohner Estlands verschlossen blieb, denn Sillamäe verfügte über den Status einer geschlossenen Stadt.

Während des Baubooms der Nachkriegszeit äußerte sich der Wunsch im gesamten Europa, sich von der historischen Umgebung, die solche Probleme hervorgerufen hatte, zu entfernen, um neue Städte zu errichten, die den Grundstein für die Entwicklung einer gut funktionierenden Gesellschaft neuen Typs legen sollten. Der Machtwechsel, der sich in der Sowjetunion in der Mitte der fünfziger Jahre des 20. Jahrhunderts vollzog, lieferte dem Städtebau der nächsten Jahrzehnte

57 Proekt planirovki žilogo poselka, 1949 [Planung einer Wohnsiedlung, 1949], Proektnyj institut GSPI 12, Leningradskij filial, A. F. Nikaev (leitender Architekt), M. A. Pospechov (Architekt), Z. N. Šalina (Ökonom), Sillamäe Muuseum, SM2Ajd/0465.

58 Sillamäe 1940.-1950. aastate miljööväärtuslike hoonestusalade teemaplaneering (Sillamäe Linnavalitsus, OÜ E-Konsult, 2009), 32. 


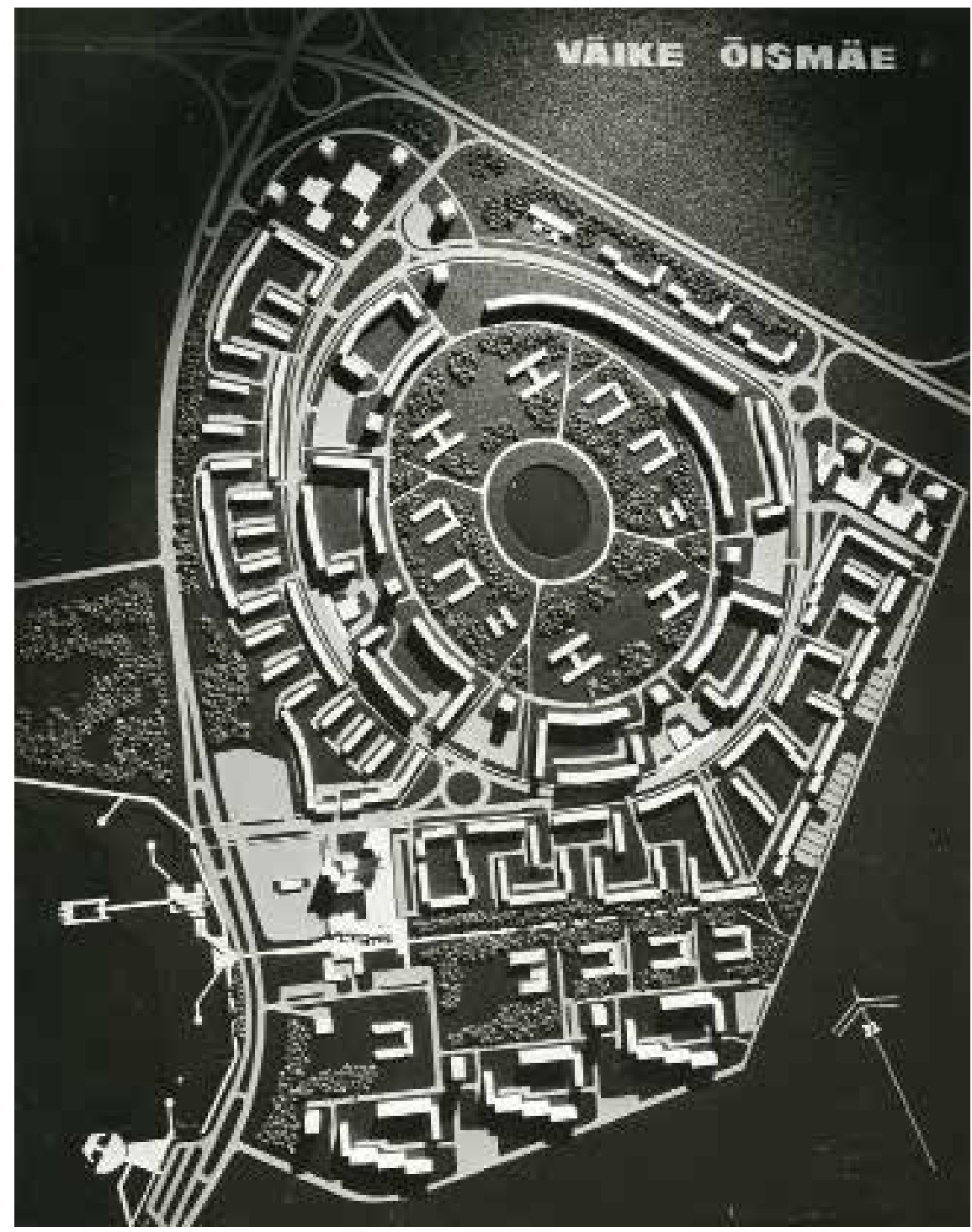

Abb. 16. Mart Port, Malle Meelak, Inessa Põldma und Kalju Luts. Die Detailplanung für den Wohnrayon Väike-Õismäe (1974). EAM, FK11137F 
eine völlig neue Richtung. ${ }^{59}$ Bei der Architektur handelte es sich nicht mehr um eine Kunstform, sondern sie diente zur Planung der Herstellung von Massenbauten und dem Entwerfen neuer Stadtteile mit freier Stadtplanung. Nach dem Beschluss über die Entwicklung des Wohnungsbaus in der gesamten Sowjetunion wurde in Estland im Jahre 1957 eine Verordnung erlassen, mit der man sich dazu verpflichtete, den Wohnungsmangel innerhalb von zwölf Jahren zu beseitigen. ${ }^{60}$ Da ein Drittel des Neubauumfangs der gesamten Republik in der Hauptstadt geplant war, musste man innerhalb von einem Dutzend Jahren neben der alten eine neue Stadt Tallinn aufbauen. Dieser Plan, der utopisch erscheint, wurde tatsächlich umgesetzt - im Laufe von fast drei Jahrzehnten wurden die drei größten Neubaugebiete Mustamäe (1962-1973), Väike-Õismäe (1973-1978) und Lasnamäe (1977-1990) zu den Hauptbaustellen von Tallinn, wohin insgesamt Wohnungen für ungefähr 300.000 Menschen geplant worden waren. ${ }^{61}$ Von der städtebautechnischen Konzeption her ist Väike-Õismäe am interessantesten (Malle Meelak und Mart Port, 1968) ${ }^{62}$ (Abb. 16). Dort basiert die städtebauliche Lösung, die das konzentrische Schema der Idealstadt befolgt, auf dem zentralen künstlichen Gewässer und auf den um es herum liegenden Zonen, die jeweils über unterschiedliche Funktionen verfügten. Auf dem Parkgebiet neben dem Teich sind Sportplätze, Kindergärten und Schulen, um sie herum stehen neunstöckige Wohnhäuser abwechselnd mit sechszehnstöckigen Hochhäusern und niedrigen Handels- und Dienstleistungszentren, in den Grenzgebieten befinden sich fünfstöckige Wohnhäuser. Der Abwechslungsreichtum der Höhe der Gebäude sollte eine interessante Silhouette von vielen Standorten her schaffen. Mit den geschlossenen Aussichten, die als Folge der bogenförmigen Straßen

59 Nach der Verordnung aus dem Jahre 1955 „Über die Liquidierung der Übertreibungen auf dem Gebiet des Projektierens und der Bautätigkeit" wurde eine ästhetische Baukunst, die in die Vergangenheit blickte, aufgegeben und zum Funktionalismus zurückgekehrt, um seiner Rationalität, den modernen Technologien und Materialien Folge zu leisten (Erlass des Zentralkomitees der KPdSU und des Ministerrates der UdSSR „Liialduste likvideerimisest projekteerimise alal ja ehitustegevuses", Rahva Hääl, 10. XI 1955).

60 Erlass des Zentralkomitees der KP Estlands und des Ministerrates der Estnichen SSR nr 337, 8. X 1957 „Abinõudest elamuehituse arendamiseks Eesti NSV-s“, Eesti NSV seadusandlike aktide kronoloogiline kogu. 1957. a., II Bd (Tallinn, 1963), 415-419.

61 Die in den Klammern angeführten Baujahre sind ungefähre Jahreszahlen, die auf unterschiedlichen Quellen basieren, siehe zum Beispiel Juta Lutsar, „Uued elamurajoonid“, Eesti Arhitektuur 1. Tallinn (Tallinn: Valgus, 1993), 41-45; Dimitri Bruns, Tallinn. Linnaehituslik kujunemine (Tallinn: Valgus, 1993), 170-173.

62 ERA, f. T-14, n. 4-6, s. 8855; ERA, f. T-14, n. 4-6, s. 9086. 
entstanden, und durch die Platzierung der Wohnhäuser, so dass sich Hofgelände bildeten, versuchte man den Effekt eines Straßenraumes zu erzielen, der für eine historische Stadt mit geschlossenen Stadtvierteln und um sich schlängelnden Straßen charakteristisch ist. Es wurde angenommen, dass sich so ein Gemeinschaftsgefühl entwickelt - „gemeinsame Sorge und Verantwortung für den Zustand der Ordnung, Sauberkeit und Begrünung beim eigenen Heim ${ }^{\prime \prime 6}$.

Die immer mehr ansteigende Produktion industrieller Musterwohnhäuser linderte zwar den Wohnungsmangel, wurde aber zum Anlass einer schnelleren Urbanisierung und den damit einhergehenden Veränderungen in der Lebensqualität der Menschen. Die urbanen Visionen des Modernismus sind im Vergleich zu allen früher beschriebenen Beispielen der Realität am nächsten gekommen, dies aber nur in der materiellen Form der Neubaugebiete mit freier Stadtplanung. Das utopische Ideal von einer lichtdurchfluteten und gut funktionierenden Stadt, die den Idealen des Gemeinschaftslebens entspräche, ist unerreichbar geblieben.

In den siebziger Jahren des 20. Jahrhunderts entfesselte sich in Estland ein öffentlicher Widerstang gegen die langweilige und graue Umgebung, die aus montierbaren Betonelementen errichtet wurde. In der Zeitung „Sirp ja Vasar" (deutsch: „Hammer und Sichel“) entfaltete sich eine Diskussion unter der Rubrik „Die Stadt, in der wir leben“, die über das ganze Jahr 1979 hin andauerte. Die Kritik war gegen die Neubaugebiete gerichtet, wo ungeachtet der Wirtschaftlichkeit keine vollwertige natürliche Umwelt entstanden war. Eine theoretische Sinngebung der Stadt erfolgte durch mehrere Architekten, ${ }^{64}$ die, während sie auf die Geschichte des Urbanisierungsprozesses zurückblickten, die Schlussfolgerung zogen, dass der zeitgenössische Mythos der Idealstadt in Form von den neuen Städten mit freier Stadtplanung sich nicht von den Vorgängern unterscheidet.

Den Hintergrund der neuen städtebaulichen Richtungen der achtziger Jahre des 20. Jahrhunderts bildete die postmoderne Architekturideologie, die das Ökologische und den Kontext, die Geschichtlichkeit und die Milieuwerte in den Vordergrund stellte. Anderswo in der Welt hatte die Wende von der modernistischen Stadt oder der Stadt des statistischen

63 Mart Port, „Väike-Õismäest ja ajategurist“, Ehitus ja Arhitektuur, 2 (1987), 59.

64 Harry Šein, „Tühjusest, millest siis muust“, Sirp ja Vasar, 25.VIII 1978; Ignar Fjuk, „Uuslinnalisi lahtimõtestamisi“, Sirp ja Vasar, 5. 5. 1979, 11. 5. 1979. 
Menschen in Richtung auf eine Stadt des sozialen Menschen bereits in den sechziger Jahren des 20. Jahrhunderts angefangen. Kevin Lynch, Jane Jacobs und Christopher Alexander behaupteten, dass die Stadt nicht hierarchisch organisierbar und keine mechanisch funktionierende Maschine sei, sondern ein Prozess, der kompliziert und schwer steuerbar sei. Den Aufgaben des Städteplaners sah man nicht mehr in der Platzierung der Häuser an vorgegebenen Orten, sondern in der Planung der Prozesse.

\section{DIE UTOPIE DER PLANUNG DER ZUKUNFT}

Der modernistische Mythos des Fortschritts brachte Versuche mit sich, eine lichte Zukunft Hilfe der politischen Staatsmacht und großzügigen Stadtplanungen herbeizuführen. Auf das Utopische der weitreichenden Planung hat bereits Karl Popper aufmerksam gemacht, der überzeugt ist, dass die Entwicklung der Welt nicht voraussagbar ist und man sie auch nicht im Voraus planen kann. Seinen Standpunkt erläutert er durch Beispiele aus der Geschichte des historizistischen Denkens, indem er den unheilvollen Einfluss solch eines Denkens auf die gesellschaftlichen und politischen Ideen angefangen mit Heraklit von Ephesos und Platon bis hin zu Hegel und Marx illustriert. ${ }^{65}$

Die Methode, die zum Historizismus den Gegensatz bildet, bezeichnet Karl Popper als „,eine allmähliche soziale Ingenieurskunst“, wobei man versucht, den Wohlstand der Menschen durch kleine Umgestaltungen zu erreichen. Eine solche Methode rechtfertigt er mit der Behauptung, dass nur ein kleiner Teil der sozialen Institutionen bewusst geplant sind, während der größere Teil sich einfach als Folge der unbeabsichtigten menschlichen Tätigkeit entwickelt habe. ${ }^{66}$ Als Gegensatz zum Vorangegangenen beschreibt Karl Popper die holistische ${ }^{67}$ oder „utopische Ingenieurskunst ${ }^{\prime \prime 6}$. Das Ziel der Anhänger des utopischen Holismus bestehe darin, die gesamte Gesellschaft gemäß eines exakten Plans oder Entwurfs umzugestalten. Sie geben sich nicht mit dem „Herumbasteln Schritt für Schritt" und mit dem „Zappeln mit Müh und Not" zufrieden, sondern wollen radikalere Methoden anwenden, die der zentralisierten Planung zu eigen sind..$^{69}$

65 Karl Popper, Historitsismi viletsus (Tallinn: Olion, 2000), 12-16.

66 Ebd., 84-88.

67 Den Utopismus und Historizismus verbindet der Holismus, der für beide charakteristisch ist (griechisch holos - ganz, gesamt).

68 Popper, Historitsismi viletsus, 88, 97-105.

69 Ebd, 88-97. 
Die Kritik der Vorplanung der Gesellschaft Karl Poppers kann auch mit der Städteplanung in Verbindung gebracht werden. Von der Utopie der Planung zeugen die meisten aus der Sowjetzeit stammenden Städteplanungen für die estnischen Städte. Ihre stetige Veränderung und Anpassung an die Realität führt uns die Irrealität der Pläne, die weitreichende und große Umgestaltungen entwerfen, vor. Demnach gilt hier die Kritik der historizistischen Planung von Karl Popper - die Verwirklichung der großzügigen Planungsentwürfe erwies sich als eine Utopie.

Antiutopische Ansichten, die zu den Utopien einen Gegensatz bilden, vertreten mehrere Denker, die ähnlich wie Karl Popper konsequente und konservative Entwicklungen befürworten. Friedrich August von Hayek meint, dass der Rationalismus der Utopien den Gegensatz zur natürlichen spontanen Entwicklung bildet. ${ }^{70}$ Laut der Behauptung von Michael Joseph Oakeshott liege der Gesellschaft der organische Zuwachs der Traditionen zugrunde und nicht ihre rationelle Rekonstruierung oder Revolution. Seiner Meinung nach führt die Gleichsetzung des Utopismus mit dem Rationalismus und dem Perfektionismus zur Politik der Eintönigkeit, wo kein Raum mehr für die Vielseitigkeit ist. ${ }^{71}$ Jurij Lotman lenkt die Aufmerksamkeit auf die Zerstörung der früheren Kulturschichten, die mit der Gründung von neuen Städten einhergeht. Er findet, dass, wenn man versucht, solche idealen künstlichen Städte zu errichten, dies die Verneinung jener Strukturen bedeutet, die sich historisch herausgebildet haben, und die Zerstörung von allem Alten. Der geschichtslosen rationalen Utopiestadt fehlt es an den „semiotischen Reserven der Vergangenheitstexte“. ${ }^{72}$ Die Ziele und Folgen der Utopie als totale Gesellschaft hat Ralf Dahrendorf folgendermaßen beschrieben: „Wer utopische Pläne umsetzen möchte, muss zuerst die Leinwand der wirklichen Welt sauberwischen. Das ist eine brutale Vernichtungsarbeit. Zweitens muss man noch eine neue Welt aufbauen, das bringt aber zwangsläufig Fehler und Fehlschläge mit sich [...]."73.

Wenn man die historischen Entwicklungen der Städte verallgemeinern möchte, dann hat man in jedem neuen Zeitabschnitt versucht, der

70 Friedrich August Hayek, Hukutav upsakus (Tallinn: Olion, 1997), 142-156; Friedrich August Hayek, Tee orjusesse (Tallinn: EBS Print, 2001), 43-54, 124-145.

71 Michael Oakeshott, Rationalism in Politics (London: Methuen, Totowa, N. J.: Rowman and Littlefield, 1977), 5-6.

72 Juri Lotman, Semiosfä̈rist (Tallinn: Vagabund, 1999), 332-333.

73 Ralf Dahrendorf, Reflections on the Revolution in Europe (New York: Random House, 1990), 61-62. 
kommenden Zukunft Platz zu schaffen. Aber das ist immer verhindert worden und hat sich in die Länge gezogen oder ist wegen der utopischen Pläne ganz und gar gescheitert. Es ist nicht möglich, das früher Gebaute komplett zu beseitigen und so wird das Neue niemals fertig. Wenn es in unseren Städten überhaupt etwas Standhaftes gibt, dann einzig und allein diese steten Vorbereitungen, um etwas Dauerhaftes zu schaffen, die Tatsache, dass die endgültige Lösung ständig weiter in die Ferne rückt, sowie der pausenlose Umbau, die ununterbrochene Renovierung und die Anpassung an neue Notwendigkeiten, wie Boris Groys treffend notiert hat. ${ }^{74}$

Die brutale Zerstörungsarbeit, welche die utopischen Pläne mit sich bringen, hat sich in den Altstädten Estlands zum Teil realisiert. Die Spuren von städtebaulichen Ideen, die nicht zu verwirklichen waren, sind in den Denkmalschutzzonen deutlich zu sehen. So müssen wir es als für wahr anerkennen, dass in den heutigen Altstädten die lange Geschichte der estnischen Städte auf der einen Seite zwar von den Architekturschichten der verschiedenen Zeitalter wiederspiegelt wird, auf der anderen Seite aber von einer ungleichmäßigen Bebauungsstruktur, deren kontinuierliche Entwicklung immer wieder von unterschiedlichen Imperien, aber auch von Städtebauweisen, die sich erneuert haben, unterbrochen wurde. Im Straßenbild der Altstädte sind die ungleiche Höhe der Bebauung und die Lücken der unbebauten Grundstücke, welche ein einstmaliges Ende und neue Anfänge kennzeichnen, typisch. Der Denkmalschutz erhielt als Erbe eine jahrhundertelange Geschichte, aber auch Gegensätze widerspiegelnde Altstädte.

\section{DIE UTOPIEN DER NOSTALGIE DER VERGANGENHEIT}

Obwohl die bis jetzt vorgetragenen Beispiele der Geschichte des Städtebaus eher ein schlechtes Licht auf die utopischen Ideen geworfen haben, können die Zusammenhänge zwischen Utopien und Ideologien auch als eine positive Erscheinung gesehen werden. Wenn eine Ideologie zur Wirklichkeit wird, dann versucht diese Utopie dennoch vor der Wirklichkeit zu flüchten oder eine neue und bessere Realität zu entdecken. Also können Utopien auf der einen Seite wie Szenarien, welche die Wirklichkeit verbessern und welche die Kritik an der herrschen-

74 Boris Groys, „Linn tema turistliku reprodutseeritavuse ajastul“, Vikerkaar, 4-5 (2004), 85. 
den Ideologie oder an dem Wertesystem zum Anlass hatten, betrachtet werden. ${ }^{75}$

Als Gegenreaktion auf den schnellen Zuwachs der Großstädte des industriellen Zeitalters veröffentlichte Ebenezer Howard ein Idealschema für Gartenstädte (Garden Cities of To-Morrow, 1898). Es stellt ein radial-konzentrisches Diagramm dar, wo neben der zentralen Hauptstadt sechs Satellitenstädte stehen, die durch ein rationelles Straßennetz miteinander verbunden sind. Ebenezer Howard sah die Großstadt der Zukunft als ein Netzwerk der Kleinstädte und diese Konzeption erwies sich im 20. Jahrhundert als eine radikale soziale Reform und als verhältnismäßig lebenskräftig, indem sie über einen großen Einfluss auf die Städteplanung verfügte. ${ }^{76}$

Obwohl die Suche nach einer neuen und besseren Welt im Regelfall in die Zukunft gerichtet ist, kann man jedoch auch Zeitabschnitte anführen, welche die Vergangenheit idealisieren. Als ein Beispiel hierfür gilt die als Gegenreaktion auf die intensive Verstädterung, die in der Mitte des 19. Jahrhunderts anfing, entstandene Vergangenheitsnostalgie. William Morris beschreibt in seinem 1890 erschienenen Buch News from Nowhere als Gegensatz zur zeitgenössischen Stadt die Stadt der Zukunft, wo eine mittelalterliche Idylle herrscht, die auf freiwilliger Arbeit basiert. Die Utopie von William Morris wiederspiegelte den schopenhauerartigen Pessimismus und die Ängste vor der kapitalistischen technologischen Entwicklung. Einer von Morris' Gesinnungsgenossen war John Ruskin, der, während er sich Sorgen um das Verlorengehen der Identität der Altstädte machte, auf den Wert der alten Stadtviertel und der dunklen Straßen aufmerksam machte. Indem John Ruskin die Erneuerung von Paris kritisierte, sah er den davon ausgehenden Einfluss auf die anderen historischen Städte Europas voraus. ${ }^{77}$

Eine der Personen, über die in der Geschichte des Restaurierens am meisten diskutiert worden ist, war Eugène Emmanuel Viollet-le-Duc, der den Inhalt des Restaurierens in der ganzen Welt beeinflusste. Die Restaurierung erhielt eine neue Bedeutung, die von Eugène Emmanuel Viollet-le-Duc folgendermaßen definiert wurde: „Einen Bau zu restau-

\footnotetext{
75 Donskis, „Ideoloogia ja utoopia“, 2158-2159.

76 Ebenezer Howard, Garden Cities of To-Morrow, herausgegeben und Vorwort von Frederic James Osborn (Cambridge, Massachusetts: M.I.T Press, 2001).

77 Jukka Jokilehto, A History of Architectural Conservation (Oxford: Butterworth-Heinemann, 2006), 180-181.
} 
rieren bedeutet nicht seine Erhaltung, seine Ausbesserung und auch nicht seinen Wiederaufbau; das bedeutet ihn in einen solchen vollständigen Zustand zu bringen, in welchem er noch nie gewesen ist. ${ }^{478}$ So dominierten in der Spätromantik des 19. Jahrhunderts die Anbetung der Vergangenheit und die Wiederherstellung der Monumente der Geschichte. Eine solche zurückblickende Erscheinung, die sich als Kritik der vorhandenen Ordnung gegenüber äußert und die Vergangenheit hochschätzt, stellt eine der möglichen Erscheinungsformen der Utopie dar.

Der in der Mitte des 20. Jahrhunderts in Europa eingesetzte Schutz der historischen Städte kann als eine den Utopien charakteristische kritische Gegenreaktion auf die modernistische Politik der Stadterneuerung, die keinen Wert auf das Kulturerbe legte, interpretiert werden. In Estland ging mit der Denkmalschutzbewegung zur Erhaltung der Altstädte der Widerstand gegen das totalitäre sowjetische Regime einher. So erhielt der Denkmalschutz eine verborgene Schattierung des Widerstands, indem er die Aureole des Überträgers der nationalen Werte trug. Zugleich sind gerade die Denkmalschützer für Entwicklungshemmer der Städte gehalten worden. Den heutigen Denkmalschutz hat man als Totalschutz behandelt, den man entsprechend der Theorie des Utopismus als eine Erscheinung der Selbstdurchsetzung interpretieren könnte. Somit kann der Denkmalschutz auf der einen Seite für eine Gegenreaktion auf die herrschenden Wertschätzungen gehalten werden, auf der anderen Seite ist er aber eine sich durchsetzende Institution. In beiden Fällen handelt es sich um Erscheinungen, die für Utopien charakteristisch sind. Diesen Widerspruch erklärt die Zwiespältigkeit der Utopie. Ihre eine Seite ist auf den Modernismus und den unaufhörlichen Fortschritt ausgerichtet, die andere aber auf den Antimodernismus, der sowohl den Mythos des Progresses als auch den optimistischen Glauben an die Zukunft dieser Welt in ein schlechtes Licht stellt. So können auch die Denkmalschützer als Bewahrer eines Gleichgewichts auf dem Grenzgebiet zwischen dem Neuen und dem Alten betrachtet werden.

Die Utopie balanciert immer auf der Grenze zwischen dem Vorstellungsvermögen und der Wirklichkeit, indem sie die Spannung zwischen der sozialen Harmonie und dem sozialen Konflikt hochhält. Deshalb überlebt die Utopie als doppelgesichtiger altrömischer Gott 
Janus oder als altgriechischer sich verwandelnder Meeresgott Proteus auch diejenigen, die ihm den Untergang verkünden und ihn für eine Erscheinung mit nur einem Gesicht halten. ${ }^{79}$

Lilian Hansar: The City as a UTOPIA

KEYWORDS: UTOPIA, IDEAL CITY, PLANNING, ABSOLUTISM, TOTALITARIANISM.

Summary:

An ideal world has been dreamed about throughout human history. Utopian ideas about ideal societies, countries, or cities have been presented primarily as philosophies and theories, as artistic or literary fantasies, but attempts have also been made to actually implement them. Thus social, political and humanist utopias have influenced the planning and building of cities. Especially radical changes have been planned at the beginning of new political formations and urban planning periods. Therefore, utopian urban planning ideas are always connected to the ruling power - absolutism and totalitarianism. Being in the service of new ideologies, the utopian building plans for ideal cities can be viewed as the visual and aesthetic forms of social and political ideas. The article provides a survey of Renaissance-era ideal cities, the cities from the Enlightenment that reflected ideal order, and the total modernisation of cities in the 20th century. Attention is directed at utopias with nostalgia for the past and ones that plan for the future. Similarly to Europe, a survey of the various construction periods of Estonian cities provides a basis to state that the changes and planning that have occurred during their development is connected to phenomena characteristic of utopias.

CV:

Lilian Hansar has graduated Estonian Academy of Art as an architect (1975), she has obtained masters degree on protection and restoration of heritage (2002) and her $\mathrm{PhD}$ thesis (2010) treated the transformation

79 Donskis, „Ideoloogia ja utoopia“, 2157-2162. 
of town structures in Estonian small towns from the 13th to 20th century. Hansar is since 2007 professor and Head of the Department of Protection and Restoration of Heritage at the Estonian Academy of Arts. Her publications mainly concentrate on the history and protection of city building as well as its meaning as a milieu. 
